\title{
Hydrogen storage in hybrid of layered double hydroxides/reduced graphene oxide using spillover mechanism
}

\author{
Ali A. Ensafi*, Mehdi Jafari-Asl, Afshin Nabiyan, Behzad Rezaei, Mohammad \\ Dinari
}

Department of Analytical Chemistry, College of Chemistry, Isfahan University of Technology, Isfahan 84156-83111, Iran

Abstract

New efficient hydrogen storage hybrids were fabricated based on hydrogen spillover mechanism, including chemisorptions and dissociation of $\mathrm{H}_{2}$ on the surface of layered double hydroxides (LDH) and diffusion of $\mathrm{H}$ to reduced graphene oxide (rGO). The structures and compositions of all of the hybrids (LDHs/rGO) have been verified using different methods including transmission electron microscopy, $\mathrm{X}$-ray diffraction spectroscopy, infrared spectroscopy and Brunauer-Emmett-Teller analysis. Then, the abilities of the LDHs/rGOs, as hydrogen spillover, were investigated by electrochemical methods. In addition, the LDHs/rGOs were decorated with palladium, using redox replacement process g and their hydrogen spillover properties were studied. The results showed that the hydrogen adsorption/desorption kinetics, hydrogen storage capacities and stabilities of $\mathrm{Pd}^{\#} \mathrm{LDH} / \mathrm{rGO}$ are better than $\mathrm{Pd} / \mathrm{rGO}$. Finally presence of different polymers (synthesis with monomers, 4-aminophenol, 4-aminothiophenol, $o$ phenylenediamine and $p$-phenylenediamine) at the surface of the Pd\#LDH/rGOs on hydrogen storage were studied. The results showed that presence of $o$-phenylenediamine and $p$-phenylenediamine improves the kinetics of the hydrogen adsorption/desorption

*Corresponding author. Tel.: +98 31 33912351. Fax: +98 31 33912350. E-mail address:

Ensafi@cc.iut.ac.ir, aaensafi@gmail.com. 
27 Keywords: Spillover Mechanism, Redox Replacement, Hydrogen Storage, Graphene,

and increase the capacity of the hydrogen storage. Layered Double Hydroxides.

\section{Introduction}

Hydrogen, as a source of energy, has several advantages including ease of synthesis, its non-polluting nature and its abundance. A suitable method for storage of hydrogen is important in vehicular applications. One of cost effective hydrogen storage system is proton exchange membrane fuel cell for on board vehicular applications. Development of new hydrogen storage materials is one of the major technological barriers and challenges [1-4].

Hydrogen spillover arises in hydrogen catalyzed reactions on supported metal catalysts. Dihydrogen molecules dissociate on the metal part of the catalyst. Some hydrogen atoms remain attached to the metal, whilst others diffuse to the support. [5-7]. An applicable spillover sorbent should: (a) permit the diffusion of $\mathrm{H}_{2}$ or $\mathrm{H}$ atoms in a well-dispersed pore lattice, (b) have most of the interior pore surface area disposable to encounter with spillover $\mathrm{H}_{2}$ or $\mathrm{H}$, and (c) be lightweight to maximize the gravimetric hydrogen uptake. Thus, the hydrogen uptake in mesoporous carbon and metal-organic frameworks (MOFs), which have suitable surface area and proper porosity and lowdensity, can be augmented substantially by hydrogen spillover [8-11].

Graphene, due to its high surface area and chemical durability, has a potential as a hydrogen adsorbent. Experimental and theoretical studies confirm that graphene can adsorb hydrogen by physisorption and/or chemisorption mechanisms. Reduced graphene 
oxide (rGO) has unrivalled properties to serve as a hydrogen storage material. Therefore, this property is improved by combining rGO with selective nanostructures and compounds. Two approaches can be used to improve the surface of rGO: (i) via creation of nanometer-sized pores to create deeper potential wells and dramatically raise the surface area for adsorption and (ii) by doping with some elements (such as $\mathrm{Al}, \mathrm{Li}, \mathrm{Ca}, \mathrm{V}$, $\mathrm{Fe}, \mathrm{Ni}, \mathrm{Cu}, \mathrm{Zn}, \mathrm{Pd}, \mathrm{Pt}, \mathrm{Ru}$, and $\mathrm{TiO}_{2}$ ) to increase its interaction ability with the hydrogen substrate $[12-21]$

In this work, modified layered double hydroxides (LDHs) have been extensively used to develop functional nanomaterials. A combination of physisorption of hydrogen in porous materials (using $\mathrm{rGO}$ ), chemisorption of hydrogen molecules at $\mathrm{Al}-\mathrm{M}(\mathrm{M}: \mathrm{Cu}$, $\mathrm{Ni}, \mathrm{Zn}$ ) decorated with $\mathrm{Pd}$ and finally formation of metal hydrides, were used to increase the advantages and reduce the drawbacks of the new nanocomposite as a hydrogen sorbent. Here, the feasibilities and capabilities of the LDH/rGOs and Pd\#LDH/rGOs (using redox replacement) as new sorbents were investigated for hydrogen storages at room temperature and pressure. Finally presence of different polymers including 4aminophenol, 4-aminothiophenol, $o$-phenylenediamine and $p$-phenylenediamine at the surface of the Pd\#LDH/rGOs were studied on their hydrogen storage capacities too. The results showed that the hydrogen adsorption/desorption kinetics, hydrogen storage capacities and stabilities of $\mathrm{Pd}^{\#} \mathrm{LDH} / \mathrm{rGO}$ are better than $\mathrm{Pd} / \mathrm{rGO}$.

\section{Experimental}

\subsection{Materials and reagents}

Potassium tetrachloropalladate 98\% (CAS Number: 10025-98-6), aluminum nitrate $\geq 98 \%$ (CAS Number: 7784-27-2), copper nitrate $\geq 98 \%$ (CAS Number: 10031-43-3), 
zinc nitrate $98 \%$ (CAS Number: 10196-18-6), nickel nitrate $\geq 98.5 \%$

Number: 13478-00-7), graphite 99.99\% (CAS Number: 7782-42-5), ethylene glycol 99.8\% (CAS Number: 107-21-1), 4-aminophenol 98\% (CAS Number: 123-30-8), 4aminothiophenol 97\% (CAS Number: 1193-02-8), o-phenylenediamine 98\% (CAS Number: 95-54-5) and p-phenylenediamine 99\% (CAS Number: 106-50-3) were purchased from Sigma-Aldrich. All other chemicals were of analytical grade and purchased from Merck. Double distilled water was used for preparation of all the solutions.

\subsection{Characterization methods}

Fourier-transform infrared (FT-IR) spectra of the LDH hybrids were recorded using a JASCO 680 spectrophotometer over the wavenumber range of $400-4000 \mathrm{~cm}^{-1}$. Field emission scanning electron microscopy (FE-SEM) and energy dispersive X-ray spectroscopy (EDS) (XL, Philips) were employed to characterize Pd\#Al-M/LDH-rGOs and $\mathrm{Al}-\mathrm{M} / \mathrm{LDH}-\mathrm{rGOs}(\mathrm{Cu}, \mathrm{Ni}$, and $\mathrm{Zn})$ morphologies and to explore the presence of different LDH-rGOs. Transmission electron microscopy (TEM) was performed using a Philips CM120. X-ray photoelectron spectroscopy (XPS) measurements were performed using an ultra-high vacuum (UHV) set-up equipped with the concentric hemispherical analyzer and VG Microtech twin anode. XR3E2 X-ray source was used as incident radiation. X-ray diffraction (XRD) analysis was carried out with a Bruker D8/Advance $\mathrm{X}$-ray diffractometer and with $\mathrm{Cu}-\mathrm{K}_{\mathrm{a}}$ radiation. A high performance volumetric physisorption apparatus at $77{ }^{\circ} \mathrm{K}$ Brunauer-Emmett-Teller (BET) and Barrett-JoynerHalenda $(\mathrm{BJH})$ were used to investigate the real surface of different LDHs before and after redox replacement of the $\mathrm{M}$ with $\mathrm{Pd}$. To determine the LDHs and the graphitization degree of $\mathrm{rGO}$, thermogravimetric analysis (TGA) and derivative thermogravimetry 
102 (DTGA) were performed using Rometric simultaneous thermal analysis. The heating 103 program was performed in a temperature range from 30 to $850{ }^{\circ} \mathrm{C}$ with a heating rate of

104

123 Finally, the obtained graphene oxide was dispersed in water $\left(1.0 \mathrm{mg} \mathrm{mL}^{-1}\right)$, which was 124 put in an ultrasonic bath for $2 \mathrm{~h}$, to convert it to exfoliated graphene oxide (EGO) [22]. $10{ }^{\circ} \mathrm{C} \min ^{-1}$.

Electrochemical analysis was performed by means of electrochemical galvanostatic measurement, Model PGSTAT 30 potentiostat/galvanostat (Eco-Chemie, the Netherlands), that was controlled by a microcomputer at ambient temperature and in $0.50 \mathrm{~mol} \mathrm{~L}^{-1} \mathrm{H}_{2} \mathrm{SO}_{4}$ as an electrolyte. Three-electrode cell set-up consists of a working electrode, which is made up of a glassy carbon electrode covered by different modifiedLDHs (after redox replacement and finally after polymerization), a reference $\mathrm{Ag} / \mathrm{AgCl}$ electrode and a Pt-wire as a counter electrode was used. Data were acquired and processed using GPSE computrace software 4.9.007 and FRA computrace software.

\subsection{Synthesis of exfoliated graphene oxide and reduced graphene oxide}

Modified Staudenmaier method was used to prepare graphene oxide (GO).

Graphite powder (with a purity of $99.99 \%$ and particle size of $70 \mu \mathrm{m}$ ) was oxidized to $\mathrm{GO}$ at room temperature by chemical treatment. For this purpose, graphite $(1.0 \mathrm{~g})$ was added into a mixed solution containing conc. sulfuric acid $(20 \mathrm{~mL})$, conc. nitric acid (10 $\mathrm{mL})$ and potassium chlorite $(10.0 \mathrm{~g})$. The mixture was stirred for $100 \mathrm{~h}$. The resulting mixture was filtered, rinsed with $5.0 \mathrm{wt} \% \mathrm{HCl}$ aqueous solution, and washed with water until the $\mathrm{pH}$ of the filtrate was neutral. The solid product was dried at room temperature. The reduction of EGO to $\mathrm{rGO}$ was performed as follows: $100 \mathrm{~mL}$ of EGO suspension $\left(1.0 \mathrm{mg} \mathrm{mL}^{-1}\right)$ was prepared in double distilled water. The suspension was kept at $0{ }^{0} \mathrm{C}$ then five times of $\mathrm{NaBH}_{4}$ (ratio to $\mathrm{rGO}$, w/w) was added dropwise to the 
128 suspension to reduce the EGO to reduced graphene oxide. The resulting suspension was 129 filtered and washed with water several times. Finally, it was dried at room temperature $130[23]$.

\subsection{Decoration of Pd nanoparticles on $r G O$}

133

134 135 136

Pd-nanoparticles were deposited on rGO sheets by chemical reduction method using potassium tetrachloropalladate $\left(\mathrm{K}_{2} \mathrm{PdCl}_{4}\right)$ in ethylene glycol-water $(2 / 1$, v/v) solution. In a typical procedure, $100 \mathrm{mg}$ of rGO plus $80 \mathrm{mg}$ of $\mathrm{K}_{2} \mathrm{PdCl}_{4}$ was dispersed in $100 \mathrm{~mL}$ of double distilled water. It was then added into $200 \mathrm{~mL}$ of ethylene glycol in a 500-mL flask. To uniformly disperse rGO in the ethylene glycol-water solution, the mixture was ultrasonically treated for $1 \mathrm{~h}$. The reaction mixture was then stored at 100 ${ }^{\circ} \mathrm{C}$ for $12 \mathrm{~h}$ under constant stirring. During this time, Pd nanoparticles were decorated on rGO (Pt-rGO). Finally, the solid produced, Pt-rGO, was filtered and washed with water several times. The resulting product was dried in a vacuum desiccator at $60{ }^{\circ} \mathrm{C}$ for $12 \mathrm{~h}$ [23].

\subsection{Preparation of LDHs-rGO hybrids and the hydrogen sorbents}

Al-M/LDH-rGOs (M: Ni, Cu, Zn) were synthesized via ultrasonic irradiation as a simple, green and fast method. For preparation of Al-M/LDH-rGO, first $0.070 \mathrm{~g}$ of rGO was dispersed in an aqueous solution $(2.06 \mathrm{~mL})$ containing $9.9 \mathrm{mmol} \mathrm{NaOH}$. Subsequently, $1.4 \mathrm{~mL}$ of a mixture solution of $2.80 \mathrm{mmol}$ of $\mathrm{M}\left(\mathrm{NO}_{3}\right)_{2} \cdot 6 \mathrm{H}_{2} \mathrm{O}$ (where $\mathrm{M}$ : $\mathrm{Ni}, \mathrm{Cu}, \mathrm{Zn}$ ) and $1.40 \mathrm{mmol} \mathrm{Al}\left(\mathrm{NO}_{3}\right)_{3} \cdot 9 \mathrm{H}_{2} \mathrm{O}$ was added to the above mixture. The resulting black suspension was stirred at $60{ }^{\circ} \mathrm{C}$ for $2 \mathrm{~h}$ under nitrogen atmosphere. The mixture was sonicated for $2 \mathrm{~h}$ under nitrogen atmosphere. The solid was recovered and 
washed with double distilled water several times and finally dried under vacuum at $80{ }^{\circ} \mathrm{C}$ 155 for $12 \mathrm{~h} \mathrm{[24].}$ $\mathrm{g}, 0.350 \mathrm{~g}$, and $0.700 \mathrm{~g}$ of $\mathrm{rGO}$ in the presence of constant amount of Al-M/LDH 158 precursor concentration. Moreover, both rGO and EGO were used to synthesize Al$159 \mathrm{M} / \mathrm{LDH}-\mathrm{rGO}$ and Al-M/LDH-EGO under the same conditions. To prepare the hydrogen sorbents, $2.50 \mathrm{mg}$ of Al-M/LDH-rGO (M: Ni, $\mathrm{Cu}, \mathrm{Zn}$ )

161

\section{Results and discussion}

3.1. Physical characterization of the LDHs and characterization of the Pd\#Al-M/LDH$r G O$

Different methods including TEM, FE-SEM, EDS, XRD, FT-IR, TGA and BET were used to investigate the characteristics of M-Al/LDH-rGOs. 
181 ratios (wt $\%)$ of $\mathrm{Al}-\mathrm{Ni} / \mathrm{LDH}$ vs. $\mathrm{rGO}(100,35,20$, and $10 \% \mathrm{w} / \mathrm{w})$. The rGO characteristic 182 peaks appeared at $3412,1717,1584,1231$ and $1050 \mathrm{~cm}^{-1}$, which are attributed to $\mathrm{O}-\mathrm{H}$ 183 stretching, carbonyl $\mathrm{C}=\mathrm{O}$ stretching, aromatic $\mathrm{C}=\mathrm{C}$ stretching, epoxy $\mathrm{C}-\mathrm{O}$ stretching and 184 alkoxy $\mathrm{C}-\mathrm{O}$ stretching. These results are in agreement with the previous reports on $\mathrm{rGO}$ 185 [26]. In pure Al-Ni/LDH (Fig. 1A), the broad peak centered at about $3469 \mathrm{~cm}^{-1}$ is 186 attributed to the $\mathrm{O}-\mathrm{H}$ stretching vibration of water molecules in the interlayer. The peak 187 at $1429 \mathrm{~cm}^{-1}$ is attributed to nitrate ions bound to $\mathrm{Ni}$ metal in $\mathrm{C}_{2 \mathrm{v}}$ symmetry. 188 Furthermore, the absorption band below $700 \mathrm{~cm}^{-1}$ is ascribed to the characteristic peak of $189 \mathrm{Ni}-\mathrm{O}$ and $\mathrm{Al}-\mathrm{O}$ vibrations in the lattice of $\mathrm{LDH}$ [27]. According to these spectra, all 190 bands due to the presence of both $\mathrm{Al}-\mathrm{Ni} / \mathrm{LDH}$ and $\mathrm{rGO}$ are observed. In addition, with 191 increasing the amount of rGO, the characteristic peak around $1700 \mathrm{~cm}^{-1}$ is increased. 192 Fig. 1B shows FT-IR spectra for different LDHs (Al-M/LDH-rGO, M: Ni, Cu, Zn) and 193 the results for all of the LDHs showed the same properties too. "Here Fig. 1" 194 XRD patterns of rGO, Al-M/LDH and the hybrids of Al-M/LDH-rGOs (M: Ni, $195 \mathrm{Cu}, \mathrm{Zn}$ ) are presented in Fig. 2. The XRD pattern of rGO exhibits a sharp peak at $24.5^{\circ}$ 196 demonstrating the oxidation of graphite to EGO and then reduction. In addition, this is 197 indicating inter planar spacing of $(002)$ at about $0.85 \mathrm{~nm}$, which is much larger than that 198 of pristine graphite $(0.34 \mathrm{~nm})$. The width of the peak is attributed to a turbostratic 199 arrangement of graphene stacked sheets. The diffraction peaks including (003), (006), 200 (012), (015) and (018) planes of typical hydrotalcite-like pure Al-M/LDH are observed. 201 The XRD pattern of hybrid of Al-M/LDH-rGO is almost identical to pure LDH. These 202 results confirm that the LDH is well anchored on the rGO sheets and overlap with the 203 rGO peak $(2 \theta=26.1)[28]$. "Here Fig. 2" 

investigated by FE-SEM and TEM too. Fig. 3 shows FE-SEM of Al-Zn/LDH-rGO (3Aa), Al-Ni/LDH-rGO (3B-a), and Al-Cu/LDH-rGO (3C-a) and also shows TEM images of Al-Zn/LDH-rGO (3A-b), Al-Ni/LDH-rGO (3B-b), and Al-Cu/LDH-rGO (3C-b). FE208 SEM images show the LDH (that prepared by ultrasonic method) has roughly 209 immobilized on the rGO sheets and also opening the sheets of rGO to rupture the LDH 210 layers. Thus, porous structure is formed over the whole hybrid domain. These TEM 211 images confirm that small platelets of LDH attached to the surface of rGO and most of 212 the LDH platelets have oriented face on the graphene substrate. The thicknesses of the 213 LDH platelets are around at $20-30 \mathrm{~nm}$ (according to the XRD results). This is due to the 214 fact that during the synthesis, the positively charge of LDH sheets interact with the 215 negatively charged rGO leading to immobilization of the LDHs between the rGO sheets 216 [24]. "Here Fig. 3"

The BET surface area and the pore structures of the fabricated sorbents were 218 characterized via $\mathrm{N}_{2}$ adsorption and desorption isotherm at $77 \mathrm{~K}$ by a surface area 219 analyzer. The surfaces area and pores diameter of the produced porous catalysts are summarized in Table 1. The results show that the surface area of the hybrids are as Al$\mathrm{Zn} / \mathrm{LDH}-\mathrm{rGO}>\mathrm{Al}-\mathrm{Ni} / \mathrm{LDH}-\mathrm{rGO}>\mathrm{Al}-\mathrm{Cu} / \mathrm{LDH}-\mathrm{rGO}$. On the other hand, the results

222 showed that after redox replacement between the divalent cations in the LDH with Pd, 223 the surface area of the prepared Pd\#Al-Ni/LDH-rGO is decreased (Table 1). This is due 224 to the blocking of micropores or mesopores of the rGO or LDH by the palladium 225 nanoparticles. Moreover, to confirm the hybridization of LDH-rGO with palladium 226 nanoparticles, palladium nanoparticles were decorated on the surface of rGO. Then, the 227 surface area of $\mathrm{Pd} / \mathrm{rGO}$ was determined using BET. The results showed that the surface 228 area of $\mathrm{Pd} / \mathrm{rGO}$ was lower than $\mathrm{Al}-\mathrm{M} / \mathrm{LDH}-\mathrm{rGO}$. These results confirm that doping of 
229 the LDH causes increasing in the surface area $v s$. doping of one metal $(\mathrm{Pd} / \mathrm{rGO})$. The

230 BET investigation also classifies the pore sizes in different sorbents. According to

231 IUPAC, pores sizes are classified into micropores, mesopores and macropores with pore

232 diameter up to 2 , from 2 to 50 , and $>50 \mathrm{~nm}$, respectively. The Barret-Jayner-Halenda

233 technique for quantifying mesopore volumes of LDHs showed that they have pores

234 diameter between 2.18 and $3.6 \mathrm{~nm}$. The results of our studies indicated that the pore

235 characteristics of the different Al-M/LDH-rGO, before and after redox replacement, have

236 the same diameter sizes. The results are given in Table 1, confirms that the pores

237 diameter for all of the sorbents are as mesopore.

238

239 Table 1

240 Surface area and the porosity of the porous synthesized solid state sorbents.

Surface area $\left(\mathrm{m}^{2} \mathrm{~g}^{-1}\right) \quad$ Pore diameter $(\mathrm{nm})$

\begin{tabular}{llllll}
\cline { 2 - 3 } Sample & Langmuir & BJH & BJH & BJH & BJH \\
& & adsorption & desorption & adsorption & adsorption \\
Al-Ni/LDH-rGO & 50.9 & 109.65 & 127.52 & 2.67 & 2.18 \\
Al-Cu/LDH-rGO & 55.70 & 104.05 & 119.13 & 2.74 & 3.6 \\
Al-Zn/LDH-rGO & 53.90 & 150.71 & 174.44 & 2.75 & 2.43 \\
Pd\#Al-Ni/LDH-rGO & 45.52 & 102.82 & 98.73 & 2.78 & 2.46 \\
Pd/rGO & 22.3 & 51.83 & 60.50 & 2.76 & 2.18 \\
\hline
\end{tabular}

241

242

TGA curves of Al-M/LDH-rGOs in nitrogen were recorded. All of the samples

243 exhibited three distinct weight loss steps: the first weight loss from 100 to $250{ }^{\circ} \mathrm{C}$ is due

244 to the release of the adsorbed water and water contents in the hybrids; the second weight 
245 loss from 300 to $450{ }^{\circ} \mathrm{C}$ corresponds to removal of nitrate anions and the 246 dehydroxylation of the LDH layers; and finally different reactions could be occurring at 247 higher temperature $\left(500-700^{\circ} \mathrm{C}\right)$. The weight loss in nitrogen is ascribed to the reduction 248 of $\mathrm{M}^{2+}$ to $\mathrm{M}^{0}$ by carbon [23]. The TGA residues of the Al-Zn/LDH-rGO, Al-Ni/LDH$249 \mathrm{rGO}$ and $\mathrm{Al}-\mathrm{Cu} / \mathrm{LDH}-\mathrm{rGO}$ hybrid materials were 25, 21 and $18 \mathrm{wt} . \%$, respectively. Redox replacement reaction was used to prepare Pd-modified Al-M/LDH-rGO 251 as the hydrogen sorbents. Divalent cations of $\mathrm{M}$ in Al-M/LDH-rGOs were used for the 252 redox replacement with $\mathrm{Pd}^{2+}$. Divalent cations cannot directly react with $\mathrm{PdCl}_{4}{ }^{2-}$, 253 whereas $\mathrm{H}^{+}$ions are crucial for the redox replacement of Pd [23]. For example, Al$254 \mathrm{Ni} / \mathrm{LDH}-\mathrm{rGO}$ was put in a solution of $2.0 \mathrm{mmol} \mathrm{L}^{-1} \mathrm{~K}_{2} \mathrm{PdCl}_{4}$ (in the presence of $0.1 \mathrm{~mol}$ $255 \mathrm{~L}^{-1} \mathrm{H}_{2} \mathrm{SO}_{4}$ ) over different times followed by rinsing with double distilled water and its 256 cyclic voltammetric response was recorded between -0.30 to $+1.50 \mathrm{~V}$ in $0.1 \mathrm{~mol} \mathrm{~L}-1$ $257 \mathrm{H}_{2} \mathrm{SO}_{4}$. The results (just for $\mathrm{Al}-\mathrm{Ni} / \mathrm{LDH}-\mathrm{rGO}$ ) of the oxidation/reduction peaks of $\mathrm{Pd}$ 258 nano-clusters at different times, for the redox replacement, are shown in Fig. 4A. These 259 results of our study confirmed that Pd nanoclusters were fabricated at the surface of Al260 M/LDH-rGO electrodes. The redox replacement of $\mathrm{Ni}^{0}$ with $\mathrm{Pd}^{2+}$ can result in the 261 formation of a mono- or sub-monolayer of Pd on the surface of the modified electrodes. X-ray photoelectron spectroscopy is employed to confirm the elemental resolution Ni XPS spectrum of Al-M/LDH-rGO shows six different types of $\mathrm{Ni}$ 267 configurations on the Al-M/LDH-rGO. Spectral fitting of the XPS data measured for Al$268 \mathrm{Ni} / \mathrm{LDH}-\mathrm{rGO}$ showed all three species (Ni metal, $\mathrm{NiO}$ and $\mathrm{Ni}$ hydroxide), as shown in 269 Fig. 4B. Existence of nickel in state of $\mathrm{Ni}^{0}$, can suggests that $\mathrm{Pd}^{2+}$ ions are partially 
270 reduced to $\mathrm{Pd}^{\circ}$ due to electron transfer from $\mathrm{Ni}$ metal in the $\mathrm{LDH}$ sheets, since the

271 reduction of $\mathrm{Pd}^{2+}$ is thermodynamically favored for redox replacement. The challenge of

272 galvanic exchange is solved by the analysis of the XPS spectrum of nickel at the LDH

273 sheets. Thus, the redox replacement process took place on Al-M/LDH-rGO (M: Ni, Cu,

$274 \mathrm{Zn})$ and Pd\#Al-M/LDH-rGO are synthesized. "Here Fig. 4"

275 The compositions of Al-M/LDH-rGOs before and after redox replacement were 276 analyzed using EDS. For example, the results of Al-Ni/LDH־rGOs are given in Table 2

277 that clearly shows the presence of $\mathrm{C}, \mathrm{O}, \mathrm{Al}$, and $\mathrm{Ni}$ elements with their weights percent

278 before and after the redox replacement. Moreover, the compositions of Pd\#Al-Cu/LDH-

279 rGO and Pd\#Al-Zn/LDH-rGO before and after redox replacement were analyzed by EDS

280 and are given in Table S-1 in the supplementary material. These results showed the

281 reduce weights percent of the divalent cations $(\mathrm{Zn}, \mathrm{Ni}, \mathrm{Cu})$ and increases the weight ratio

282 of $\mathrm{Pd}$ after the redox replacement. These results confirmed that Al-M/LDH-rGO and

283 Pd\#Al-M/LDH-rGO hybrid were successfully synthesized. Moreover, the compositions

284 of $\mathrm{Pd} / \mathrm{rGO}$ were also characterized with EDS and the results are given in Table 3 . These

285 results confirm the presence of $\mathrm{C}, \mathrm{O}$, and $\mathrm{Pd}$ in the composition of $\mathrm{Pd}-\mathrm{rGO}$. On the other

286 hand, a comparison between the amount of Pd on the surface of Pd/rGO and Pd\#Al-

$287 \mathrm{M} / \mathrm{LDH}-\mathrm{rGO}$ revealed that presence of $\mathrm{Pd}$ at $\mathrm{Pd} / \mathrm{rGO}$ was three times of $\mathrm{Pd}$ at $\mathrm{Pd \# M-}$ 288 Al/LDH-rGO.

291 Table 2

292 EDS results for the synthesized hydrogen storage sorbent, Al-Ni/LDH-rGO, before and 293 after redox replacement. 
After redox replacement Before redox replacement

\begin{tabular}{cccccc} 
Element & Line & Atomic\% & Conc. wt\% & Atomic\% & Conc. wt\% \\
$\mathrm{C}$ & $\mathrm{Ka}$ & 72.19 & 57.35 & 69.91 & 57.14 \\
$\mathrm{~N}$ & $\mathrm{Ka}$ & 1.10 & 0.79 & 2.27 & 1.62 \\
$\mathrm{O}$ & $\mathrm{Ka}$ & 11.12 & 9.20 & 11.48 & 9.35 \\
$\mathrm{Al}$ & $\mathrm{Ka}$ & 7.50 & 13.37 & 8.26 & 11.97 \\
$\mathrm{Ni}$ & $\mathrm{Ka}$ & 3.89 & 8.30 & 8.08 & 20.1 \\
$\mathrm{Pd}$ & $\mathrm{La}$ & 4.19 & 10.98 & -- & -- \\
\hline
\end{tabular}

294

295

296 Table 3

297 EDS results for Pd-rGO.

\begin{tabular}{ccccc}
\hline Element & Conc. wt\% & Line & Atomic\% & Conc. wt\% \\
\hline C & 49.03 & Ka & 71.11 & 49.03 \\
O & 10.78 & $\mathrm{Ka}$ & 13.44 & 10.78 \\
Pd & 40.19 & $\mathrm{Ka}$ & 15.45 & 40.19 \\
& 100.00 & & 100 & 100.00 \\
\hline
\end{tabular}

298

299

300 3.2. Electrochemical behaviors of the Al-M/LDH-rGO and Pd\#Al-M/LDH-rGO and

$301 \quad$ effect of different polymers on their hydrogen storage

302

303 To further investigate the hydrogen storage properties of the Al-M/LDH-rGO and

304 Pd\#Al-M/LDH-rGO, cyclic voltammetry is used too. In the anodic pathway scan,

305 hydrogen desorption plateau appeared at about $-0.12 \mathrm{~V}$, which can be attributed to the

306 following reaction: 
308 In the cathodic pathway scan, a hydrogen adsorption plateau appeared at about $-0.23 \mathrm{~V}$, 309 which can be attributed to the following reaction:

311 The cyclic voltammetry results confirm that hydrogen adsorption/desorption active sites 312 are present in Pd\#Al-M/LDH-rGO. It is also noted that the same current for both the 313 cathodic and anodic currents indicates the excellent reversibility of the solid state 314 sorbent. In this work, all voltammetric results were normalized based on the EDS results.

In order to obtain the best conditions for the maximum hydrogen capacity and stability of Pd\#Al-M/LDH-rGO for hydrogen storage, the effect of various experimental parameters including type of divalent cations in the preparation of $\mathrm{LDH}(\mathrm{Ni}, \mathrm{Zn}, \mathrm{Cu})$, presence of $\mathrm{rGO}$ or EGO in the preparation of the hybrid LDH/graphene, weight percent of the $\mathrm{LDH}(\mathrm{M}+\mathrm{Al})$ on $\mathrm{rGO}$, time of the redox replacement of $\mathrm{M}$ with $\mathrm{Pd}$ and type of the monomer for the polymerization were studied.

Our goal was the use of the hydrogen storage sorbents at room temperature and atmospheric pressure. For this condition, monolayer or sub-monolayer of $\mathrm{Pd}$ was decorated at Al-M/LDH-rGO using redox replacement. Then, $o$-phenylenediamine was used to electropolymerize Pd\#Al-M/LDH-rGO. First of all the effects of rGO and EGO on the hydrogen storage capacities in the synthesis of Al-M/LDH were investigated. For this purpose, Al-M/LDH-rGO and Al-M/LDH-EGO (10.0\% w/w LDH) were synthesized. After the redox replacement and electropolymerization of the modified electrode with $o$-phenylenediamine, typical CVs of Pd\#Al-M/LDH-rGO/ophenylenediamine and Pd\#Al-M/LDH-EGO/o-phenylenediamine in $0.50 \mathrm{~mol} \mathrm{~L}^{-1} \mathrm{H}_{2} \mathrm{SO}_{4}$ were recorded at a scan rate of $20 \mathrm{mV} \mathrm{s}^{-1}$. The results showed that the hybrid of LDHrGO has high current density (10 times) vs. the hybrid of LDH-EGO (Fig. 5A). In hydrogen spillover mechanism, after dissociation of $\mathrm{H}_{2}$ on the surface of Pd\#LDH, the 
333 created $\mathrm{H}$ is transferred to $\mathrm{rGO}$ or EGO. Therefore, the surface area and interlayer 334 distance of rGO or EGO are very important. The results showed that rGO has higher 335 capacity to storage $\mathrm{H}$ atoms than EGO.

336 The weight percent ratio of $\mathrm{M}+\mathrm{Al} / \mathrm{rGO}(100,35,20$, and $10 \% \mathrm{w} / \mathrm{w})$ is the second 337 factor that can increase hydrogen sorption capacities of the LDH hybrid. For this 338 purpose, after preparation of the modified electrode and redox replacement and 339 electropolymerization of the modified electrode with $o$-phenylenediamine, cyclic 340 voltammogram of them were recorded in $0.50 \mathrm{~mol} \mathrm{~L}^{-1} \mathrm{H}_{2} \mathrm{SO}_{4}$ with a scan rate of $20 \mathrm{mV}$ $341 \mathrm{~s}^{-1}$. As can be seen in Fig. 5B, with increasing the percent of rGO in the hybrid of $342 \mathrm{LDH} / \mathrm{rGO}$, both anodic and cathodic currents densities of the adsorption/desorption of 343 hydrogen were increased and the maximum current density was observed in $10.0 \% \mathrm{w} / \mathrm{w}$ 344 of the LDH on rGO. The improved electrochemical performance of Al-M/LDH-rGO is 345 attributed to the chemical and electronic coupling between the Al-M/LDH and rGO 346 sheets. Due to the unique electrical properties of graphene as an additive, by 347 incorporating $\mathrm{rGO}$ sheets with the LDH, the conductivity of Al-M/LDH could be 348 improved. Moreover, rGO provides a large surface area for good dispersion of Al$349 \mathrm{M} / \mathrm{LDH}-\mathrm{rGO}$, forming much smaller Al-M/LDH-rGO, as compared with the pure M$350 \mathrm{Al} / \mathrm{LDH}$. Smaller Al-M/LDH-rGO sheets in the hybrid favor the exposure of more active 351 sites for the solid state sorbent. Thus, much faster electron transfer and high real surface 352 area of the Al-M/LDH-rGO are the key factors contributing to the greatly enhanced 353 hydrogen sorbent capacity.

354 One other factor that can increase hydrogen sorption capacity is element 355 substitution. Therefore, type of divalent cations in the preparation of the LDHs (Ni, $\mathrm{Zn}$, 356 and $\mathrm{Cu}$ ) were studied. It is well known that $\mathrm{Al}-\mathrm{M} / \mathrm{LDH}-\mathrm{rGO}$ belongs to $\mathrm{A}_{2} \mathrm{~B}$ type 357 hydrogen storage alloys, in which $\mathrm{Al}$ represents the A side elements while $\mathrm{M}$ represents 
the B side elements (with the EDS results 2:1 Al:M). They act differently from each other. Generally, A side elements are Al, La, Ce, Pr, Nd, Sm, whereas B side elements are $\mathrm{Co}, \mathrm{Cu}, \mathrm{Ni}, \mathrm{Zn}, \mathrm{Mn}$, and $\mathrm{Zr}$, those can improve the gaseous and electrochemical kinetics of hydriding/dehydriding. For this purpose, different modified electrodes based on $\mathrm{Al}-\mathrm{M} / \mathrm{LDH}-\mathrm{rGO}(\mathrm{Ni}, \mathrm{Zn}, \mathrm{Cu})$ (after redox replacement and electropolymerization) were prepared and typical CVs of the electrodes were recorded in $\mathrm{H}_{2} \mathrm{SO}_{4}$ solution (Fig. 5C). As can be seen, Pd\#Al-Zn/LDH-rGO-o-phenylenediamine shows the highest current density [29]. This process can be justified by the result of a BET and TEM of the different $\mathrm{LDH}$, because Al-M/LDH-rGO shows biggest surface area and best morphology.

Finally, the redox replacement between the divalent cations in the preparation of LDHs ( $\mathrm{Ni}, \mathrm{Zn}$, and $\mathrm{Cu}$ ) and Pd should be optimized. The divalent cations in LDHs cannot directly react spontaneously with $\mathrm{PdCl}_{4}{ }^{2-}$. For example, Al-Cu/LDH-rGO was put in a solution of $2.0 \mathrm{mmol} \mathrm{L}^{-1} \mathrm{~K}_{2} \mathrm{PdCl}_{4}$ (in the presence of $0.1 \mathrm{~mol} \mathrm{~L}^{-1} \mathrm{H}_{2} \mathrm{SO}_{4}$ ) over different times followed by rinsing with distilled water and its voltammogram was recorded in $0.5 \mathrm{~mol} \mathrm{~L}^{-1} \mathrm{H}_{2} \mathrm{SO}_{4}$. Cyclic voltammograms of Pd\#Al-M/LDH-rGO in 0.5 mol L $\mathrm{L}^{-1} \mathrm{H}_{2} \mathrm{SO}_{4}$ showed oxidation/reduction peaks. These peaks confirm that the Pd monolayer is fabricated at the surface of Al-M/LDH-rGO. As the CVs show (Fig. 5C), by replacement of $\mathrm{Pd}$ with $\mathrm{Ni}, \mathrm{Cu}$ and $\mathrm{Zn}$ (using redox replacement process) the peaks current for the hydrogen adsorption/desorption increased (increases the capacity of the hydrogen sorption) and the peaks potential shifted to more positive direction (increasing in the adsorption/desorption kinetics), in comparison to Al-M/LDH-rGO (M: Ni, Zn and $\mathrm{Cu}$. Moreover, to confirm the performance of LDHs as solid state hydrogen sorbents, performance of $\mathrm{Pd} / \mathrm{rGO}$ vs. Pd\#Al-M/LDH-rGO was investigated too. To comprise the hydrogen sorbent ability of Pd/rGO vs. Pd\#Al-M/LDH-rGO, all the obtained currents 
383 (from cyclic voltammetry for different amount of $\mathrm{Pd}$ ) were normalized. The results 384 showed that the hydrogen capacity of the electropolymerized Pd\#Al-M/LDH-rGOs $(\mathrm{M}=$ $385 \mathrm{Ni}, \mathrm{Zn}, \mathrm{Cu}$ ) were higher than electropolymerized $\mathrm{Pd} / \mathrm{rGO}$, whereas the hydrogen 386 adsorption/desorption kinetics for the Pd/rGO was the same as the Pd\#Al-M/LDH-rGO.

\section{"Here Fig. 5"}

A few polymers such as polyaniline and polypyridine have been used to enhance the hydrogen storage capacity of hydrogen sorbents. The structures of these polymers are suitable to interact with molecular hydrogen by hydrogen bonding in the polymer structure, and increase the hydrogen storage capacity [30, 31]. Depending on the charge of the hydrogen species $\left(\mathrm{H}^{+}, \mathrm{H}_{2}, \mathrm{H}^{\mathrm{o}}, \mathrm{H}^{-}\right)$a combination of metallic, covalent, H-bonding, ionic, and van der Waals interactions could exist within and between the polymer chains and with the chemical hydrides $\left(\mathrm{AlH}_{\mathrm{x}}\right)$, metal hydrides $(\mathrm{M}: \mathrm{Ni}, \mathrm{Cu}, \mathrm{Zn})$ and $\mathrm{Pd}$ nanoparticle. In this study, the effect of different polymers, synthesized with their monomers such as 4-aminophenol, 4-aminothiophenol, p-phenylenediamine and $o$ phenylenediamine, were investigated on the hydrogen capacity and kinetics of the hydrogen storages. The results of our studies showed that presence of synthetic polymers such as by $p$-phenylenediamine and/or $o$-phenylenediamine at Pd\#Al-M/LDH-rGO increase the capacity and kinetics of the hydrogen storages at room temperature and pressure, whereas polymers based on 4-aminophenol and 4-aminothiophenol cause a reduction the capacity and kinetics of the hydrogen storages. For example, the results for Pd\#Al-Zn/LDH-rGO are shown in Figs. 6A, 6B, 6C and 6D. "Here Fig. 6"

On the other hand, to confirm the results of the hydrogen capacity and kinetics of Pd\#Al-M/LDH-rGO-o-phenylenediamine, $o$-phenylenediamine was electro-polymerized at the surface of an unmodified glassy carbon electrode, and then cyclic voltammogram was recorded in the potential range of -0.31 to $+1.00 \mathrm{~V}$ in $0.5 \mathrm{~mol} \mathrm{~L}^{-1} \mathrm{H}_{2} \mathrm{SO}_{4}$ solution. 
408 The results did not show any adsorption/desorption peaks in the potential range of -0.40 409 to $0.00 \mathrm{~V}$ vs. $\mathrm{Ag} / \mathrm{AgCl}$ (Fig. 7A). Moreover, the same investigations were done for $\mathrm{Cu}-$ $410 \mathrm{Al} / \mathrm{LDH}-\mathrm{rGO}$ before and after its electropolymerization with $o$-phenylenediamine. The

411 results also show low adsorption/desorption peaks in the potential range of -0.40 to 0.00 $412 \mathrm{~V}$ (Fig. 7B). Finally, cyclic voltammogram of Pd\#Al-Cu/LDH-rGO (between -0.30 to $413+1.00 \mathrm{~V})$ was recorded before and after its electropolymerization with $o$ 414 phenylenediamine. The results showed that $\mathrm{Pd \# Cu-A1/LDH-rGO} \mathrm{before}$ 415 electropolymerization has low hydrogen adsorption/desorption current density, whereas 416 after electropolymerization, the hydrogen adsorption/desorption current density increases 417 too much (Fig. 7C). All the obtained results confirm that combination of $\mathrm{LDH} / \mathrm{rGO}, \mathrm{Pd}$ nanoparticles and $o$-phenylenediamine produce high performance hydrogen sorbent.

\section{"Here Fig. 7"}

420

421

\subsection{Spillover mechanism}

Synergetic effect of Pd\#Al-M/LDH-rGO-o-phenylenediamine could be explained by spillover effect. In many cases, spillover effect has been observed for $\mathrm{H}_{2}$ storage in carbon-based materials like reduced graphene oxide and/or exploited graphene oxide-o-phenylenediamine. $\mathrm{Pd}$ nanoparticle is a typical component that can dissociate $\mathrm{H}_{2}$ to $2 \mathrm{H}$ (spillover effect). Moreover, $\mathrm{Al}$ was sued to form chemical hydride and $\mathrm{M}(\mathrm{Ni}, \mathrm{Cu}$ and $\mathrm{Zn}$ ) was used to form metal hydride [32]. Thus, hydrogen can chemisorbed and physisorbed on the surface of Pd\#Al-M/LDHs and rGO, respectively. Therefore, when Pd\#Al-M/LDH decorated on $\mathrm{rGO}$, the hydrogen capacity of the sorbent significantly increased, because rGO and/or hybrid of LDHs/rGO has high surface area and more carbon atoms with $\mathrm{sp}^{2}$ hybrid vs. EGO and/or LDHs/rGO [31].

Moreover, in Pd\#Al-M/LDH (M: Ni, Cu, Zn) three kind of metals were used to prepare the hydrogen sorbent to have synergic effect on hydrogen spillover (Al was used 
434 to form chemical hydride and $\mathrm{M}$ was used to form metal hydride and monolayer of Pd to 435 form metal cluster to dissociate hydrogen to $\mathrm{H}^{*}$ ). Cyclic voltammetry results for $\mathrm{Pd} / \mathrm{rGO}$ 436 (before electropolymerization) show very small peaks current for adsorption/desorption 437 of hydrogen because of its slow kinetic, while for Pd\#Al-M/LDH-rGO the peaks current 438 for adsorption/desorption of hydrogen are more noticeable (Fig. 8). This result confirm 439 that hydrogen can better chemisorbs on the surface of Pd\#Al-M/LDH and storage done at 440 nearly the same temperature with spillover effect.

\subsection{Linear polarization and electrochemical impedance spectroscopy} hydrogen adsorption/desorption on the surface of the solid state sorbents. The linear parts of the steady-state polarization curves indicated that hydrogen production and then storage over the solid state sorbent were kinetically controlled by charge transfer. The Tafel equation is described as follows [33]:

$$
\eta=(2.303 R T / \beta n F) \cdot \log \left(i_{0}\right)-(2.303 R T / \beta z F) \cdot \log (i)=\alpha+b \cdot \log (i)
$$

450 where $\eta(\mathrm{V})$ represents the applied overpotential, $\mathrm{b}\left(\mathrm{V} \mathrm{dec}{ }^{-1}\right)$ is the Tafel slope, I (A) is 451 the resulting current, $\alpha$ is the intercept related to the exchange current $i_{0}(A)$ and $R$ is the 452 universal gas constant. $\beta, \mathrm{n}$ and $\mathrm{F}$ are the symmetric factors, number of exchange electrons and the Faraday constant, respectively [34]. Using Eq. 3, the Tafel slope and the exchange current, as electrochemical parameters, can be measured. The apparent 455 exchange current, $\mathrm{i}_{0}$, provides information about the catalytic activity of the electrodes. 456 As shown in Table 4, the kinetic parameters for Pd\#Al-M/LDH-rGO and Pd/rGO after 457 electropolymerization with $o$-phenylenediamine showed that all of the solid state 458 hydrogen sorbents have fast kinetic with Volmer-Tafel mechanism. 
460 voltammetry are quite different experimental techniques (ac versus dc), the results

461 obtained should be comparable. Linear sweep voltammetry gives the dependence of the 462 overall hydrogen adsorption/desorption rate (measured by current density) on the applied 463 overpotential. The result of EIS analysis showed that the overall rate of the hydrogen 464 adsorption/desorption is related to both the charge-transfer

465

\section{Table 4}

467 Kinetic parameters obtained from steady-state Tafel curves for the hydrogen storages in 468 $0.5 \mathrm{~mol} \mathrm{~L}^{-1} \mathrm{H}_{2} \mathrm{SO}_{4}$ aqueous solution.

\begin{tabular}{lcc}
\hline Solid state sorbent & ${\text { (Tafel slope })^{-1}\left(\mathrm{Vdec}^{-1}\right)}^{-1}$ & $\mathrm{~A}$ \\
\hline Pd\#Al-Zn/LDH-rGO & 28.7 & 0.87 \\
Pd\#Al-Cu/LDH-rGO & 29.2 & 0.79 \\
Pd\#Al-Ni/LDH-rGO & 27.5 & 0.8 \\
Pd/rGO & 32.3 & 0.74
\end{tabular}

469

470

471 resistance, $R_{c t}$, and to the hydrogen adsorption resistance, $R_{p}$. Hence, combining these

472 two resistances in a series of $R_{c t}$ and $R_{p}$ and using the ohm's law, it is possible to plot the

473 semi-logarithmic dependence of the hydrogen adsorption/desorption rate. The activity of

474 the solid state hydrogen sorbents were also studied using EIS. Figs. 9A and 9B show

475 Nyquist plots ( $\mathrm{I}_{\mathrm{mZ}}$ imaginary impedance against $\mathrm{R}_{\mathrm{eZ}}$ real impedance) obtained at Pd\#Al-

$476 \mathrm{M} / \mathrm{LDH}-\mathrm{rGO}$ electrodes before and after electropolymerization with $o$-phenylenediamine

477 at an overpotential of $200 \mathrm{mV}$ in $0.50 \mathrm{~mol} \mathrm{~L}^{-1} \mathrm{H}_{2} \mathrm{SO}_{4}$ solution. In general, after 478 electropolymerization of $o$-phenylenediamine on the surface of Pd\#Al-M/LDH-rGO, the 
charge transfer resistance of the hydrogen adsorption/desorption was reduced. This result showed the positive effect of o-phenylenediamine at the surface of the solid state sorbent. Moreover, the effect of divalent cations (used in the synthesis of LDHs), and Pd nanoparticles decorated on rGO were investigated too. The results showed that the charge transfer resistance of the solid states are as: Pd\#Al-Zn/LDH-rGO $<$ Pd\#Al$\mathrm{Ni} / \mathrm{LDH}-\mathrm{rGO}<\mathrm{Pd} \# \mathrm{Al}-\mathrm{Cu} / \mathrm{LDH}-\mathrm{rGO}<\mathrm{Pd} / \mathrm{rGO}$. These results confirm the existence of LDHs and two and three-valent cations increases the kinetic of the electron transfer [35].

\section{"Here Fig. 9"}

\subsection{Stability of the hydrogen sorbents}

Another important feature of a hydrogen sorbent is its high durability. To assess this, the prepared Pd\#Al-M/LDH-rGO modified electrodes were used to record 500 successive cyclic voltammograms in potential range of -0.35 to $1.00 \mathrm{~V}$ vs. $\mathrm{Ag} / \mathrm{ACl}$, in $0.5 \mathrm{~mol} \mathrm{~L}^{-1} \mathrm{H}_{2} \mathrm{SO}_{4}$. The results showed that the current of the hydrogen adsorption/desorption at Pd\#Al-M/LDH-rGO were reduced to about $73 \%$ to its initial value (desorption of hydrogen). These results are shown in Figs. 10A, 10B and 10C, and confirm that the Pd/LDHs hybrids have high stability as solid state hydrogen sorbents.

In continuing our studies, presence of some polymers at the surface of Pd\#Al$\mathrm{Cu} / \mathrm{LDH}-\mathrm{rGO}$ on the stability of modified LDHs was investigated. To assess this, the prepared Pd\#Al-Cu/LDH-rGO modified electrode after electropolymerization with $p$ phenylenediamine and/or $o$-phenylenediamine, were used to record 250 successive cyclic voltammograms in potential range of -0.35 to $1.00 \mathrm{~V}$ vs. $\mathrm{Ag} / \mathrm{ACl}$, in $0.5 \mathrm{~mol} \mathrm{~L}^{-1} \mathrm{H}_{2} \mathrm{SO}_{4}$. The results showed that the current of hydrogen adsorption/desorption at Pd\#Al$\mathrm{Cu} / \mathrm{LDH}-\mathrm{rGO}-p$-phenylenediamine was reduced to $25 \%$ of its initial value, whereas for Pd\#Al-Cu/LDH-rGO-o-phenylenediamine, it was reduced to $94 \%$ of its initial value 
504 (Figs. 10D and 10E). These results showed that electropolymerization of the modified

505 LDHs with $o$-phenylenediamine produced a highly stable solid state hydrogen sorbent.

506

507

508

509

510

511

512

513

514

515

516

517 "Here Fig. 10"

In addition, the influence of type of divalent cations (in the LDHs) on the stability of hydrogen storage were also studied. For this purpose, Pd\#Al-M/LDH-rGO- ophenylenediamine modified glassy carbon electrodes $(\mathrm{M}$ : $\mathrm{Ni}, \mathrm{Zn}, \mathrm{Cu})$ were prepared and their stabilities in the hydrogen adsorption/desorption were studied using cyclic voltammetry with 500 successive cycles in the potential range of -0.32 to $1.00 \mathrm{~V}$. The results are shown in Fig. 11, and confirm that all of the LDHs have good stabilities for hydrogen adsorption/desorption. The current of hydrogen adsorption/desorption at Pd\#Al-M/LDH-rGO- $o$-phenylenediamine was reduced to just $87 \%$ of its initial value (Fig. 11, A, B and C). On the other hand, to check the effect of the existence of different LDHs on the stability of the hydrogen storage, the stability of $\mathrm{Pd} / \mathrm{rGO}$ (after immobilization on the surface of a GCE and its electropolymerization with $o$ phenylenediamine) was studied using cyclic voltammetry with 200 successive cycles in the potential range of -0.32 to $1.00 \mathrm{~V}$. The results of $\mathrm{Pd} / \mathrm{rGO}$ showed that the hydrogen adsorption/desorption current reduced to $10 \%$ of its initial current (Fig. 11D). This result confirms that existence of the LDHs on rGO increases the stability of hydrogen storage in this solid state sorbent. "Here Fig. 11"

\section{Conclusion}

(1)

Here, solid state hydrogen sorbents were prepared based on hybrid of layered double hydroxides Al-M (M: $\mathrm{Cu}, \mathrm{Ni}, \mathrm{Zn})$ and rGO. These sorbents have three features; they consist of absorbent at a porous material (hybrid of $\mathrm{LDH} / \mathrm{rGO}$ ), formation of chemical hydride (Al-H) and formation of metal hydride ( $\mathrm{Zn}, \mathrm{Cu}, \mathrm{Ni})$. Moreover, 
530 palladium is well known as an effective catalyst for reactions related to hydrogen and as

531 a hydrogen-storage metal and at room temperature and pressure conditions. Therefore, a

532 combination of $\mathrm{LDHs}$ and $\mathrm{Pd}$ nanoparticles (using redox replacement) was used to

533 prepare the hydrogen sorbents (Pd\#Al-M/LDH-rGO). To improve the kinetics of

534 hydrogen adsorption/desorption and the sorption capacities, they were covered with

535 different polymers such as 4-aminophenol, 4-aminothiophenol, $o$-phenylenediamine, and

536 -phenylenediamine. Then, the hydrogen storage parameters were investigated. The

537 results showed that presence of $o$-phenylenediamine, and $p$-phenylenediamine at the

538 surface of Pd\#Al-M/LDH-rGO increased the kinetics of the hydrogen

539 adsorption/desorption and increases the capacity of the hydrogen storage. On the other

540 hand, presence of some functional groups such as oxygen and/or sulfur on the monomer

541 (such as 4-aminophenol and 4-aminothiophenol) reduces the kinetics of the hydrogen

542 adsorption/desorption and reduces the capacity of the hydrogen storage. Finally,

543 combination of physisorption in the porous materials (rGO) with chemisorption in the

544 chemical hydride (Al), and presence of the metal hydride $(\mathrm{Cu}, \mathrm{Zn}, \mathrm{Ni})$ with interstitial

545 hydrides (Pd) are the key advantages of the proposed hydrogen sorbents with high

546 stabilities, and high adsorption/desorption kinetics.

547

548 Acknowledgements

549

550 The authors wish to thank the Iran National Science Foundation and National

551 Elites Foundation, for their support.

552

553

554 References 
555 [1] Mahboob A, Muller E, Karim A, Muckerman JT, Ciobanu CV, Sutter P. Site556 dependent activity of atomic Ti catalysts in Al-based hydrogen storage materials. J $557 \quad$ Am Chem Soc 2012;134:10381-4.

558 [2] Bao D, Gao P, Shen X, Chang Ch, Wang L, Wang Y, et al. Mechanical ball-milling 559 preparation of fullerene/cobalt core/shell nanocomposites with high electrochemical 560 hydrogen storage ability. ACS Appl Mater Inter 2014;6:2902-9.

561 [3] Schlapbach L, Züttel A. Hydrogen-storage materials for mobile applications. Nature $562 \quad 2001 ; 414: 353-8$.

563 [4] Zou MS, Huang HT, Sun Q, Guo XY, Yang RJ. Effect of the storage environment 564 on hydrogen production via hydrolysis reaction from activated $\mathrm{Mg}$-based materials. $565 \quad$ Energy 2014;76:673-8.

566 [5] Cheng H, Chen L, Cooper AC, Sha X, Pez GP. Hydrogen spillover in the context of 567 hydrogen storage using solid-state materials. Energy Environ Sci 2008; 1: 338-54.

568 [6] Wenelska K, Michalkiewicz B, Chen X, Mijowska E. Pd nanoparticles with tunable 569 diameter deposited on carbon nanotubes with enhanced hydrogen storage capacity. $570 \quad$ Energy 2014;75:549-54.

571 [7] Zhan D, Velmurugan J, Mirkin MV. Adsorption/desorption of hydrogen on Pt 572 nanoelectrodes: evidence of surface diffusion and spillover. J Am Chem Soc $573 \quad 2009 ; 131: 14756-60$.

574 [8] Forster PM, Eckert J, Heiken BD, Parise JB, Yoon JW, Jhung SH, Chang JS. 575 Adsorption of molecular hydrogen on coordinatively unsaturated $\mathrm{Ni}$ (II) sites in a 576 nanoporous hybrid material. J Am Chem Soc 2006,128:16846-50.

577 [9] Ma SQ, Zhou HC. A metal-organic framework with entatic metal centers exhibiting 578 high gas adsorption affinity. J Am Chem Soc 2006;128:11734-5. 
579 [10] Dinca M, Dailly A, Liu Y, Brown CM, Neumann DA, Long JR. Hydrogen storage 580 in a microporous metal-organic framework with exposed $\mathrm{Mn}^{2+}$ coordination sites. $\mathrm{J}$ $581 \quad$ Am Chem Soc 2006;128:16876-83.

582 [11] Vitillo JG, Regli L, Chavan S, Ricchiardi G, Spoto G, Dietzel PDC, et al. Role of 583 exposed metal sites in hydrogen storage in MOFs. J Am Chem Soc 2008,130,838658496.

585 [12] Wang Q, Sun Q, Jena P, Kawazoe Y. Potential of AlN nanostructures as hydrogen $586 \quad$ storage materials. ACS Nano 2009;3:621-6.

587 [13] Batalovic K, Koteski V, Stojic D. Hydrogen storage in martensite Ti-Zr-Ni alloy: $588 \quad$ A density functional theory study. J Phys Chem C 2013;117:26914-20.

589 [14] Shiraishi M, Takenobu T, Ata M. Gas-solid interactions in the hydrogen/single$590 \quad$ walled carbon nanotube system. Chem Phys Lett 2003;367:633-6.

591 [15] Kajiura H, Tsutsui S, Kadono K, Kakuta M, Ata M, Murakami Y. Hydrogen storage 592 capacity of commercially available carbon materials at room temperature. Appl Phys $593 \quad$ Lett 2003;82:1105-7.

594 [16] Dodziuk H, Dolgonos G. Molecular modeling study of hydrogen storage in carbon 595 nanotubes. Chem Phys Lett 2002;356:79-83.

596 [17] Alvarez E, Guillou N, Martineau C, Bueken B, Voorde BV, Guillouzer CL, et al. 597 The structure of the aluminum fumarate metal-organic framework. Angew Chem Int $598 \quad$ Ed 2015;54:3664-8.

599 [18] Fichtner M. Nanotechnological aspects in materials for hydrogen storage. Adv Eng $600 \quad$ Mater 2005;7:443-55.

601 [19] Grochala W, Edwards PP. Thermal decomposition of the non-interstitial hydrides 602 for the storage and production of hydrogen. Chem Rev 2004;104:1283-316. 
603 [20] Sano N, Taniguchi K, Tamon H. Hydrogen storage in porous single-walled carbon 604 nanohorns dispersed with Pd-Ni alloy nanoparticles. J Phys Chem C 2014;118:34026058

606 [21] Li G, Kobayashi H, Dekura S, Ikeda R, Kubota Y, Kato K, et al. Shape-dependent 607 hydrogen-storage properties in Pd nanocrystals: which does hydrogen prefer, 608 octahedron (111) or cube (100)?. J Am Chem Soc 2014;136:10222-5.

609 [22] Ensafi AA, Jafari-Asl M, Rezaei B. A new strategy for the synthesis of 3-D Pt 610 nanoparticles on reduced graphene oxide through surface functionalization, 611 Application for methanol oxidation and oxygen reduction. Electrochim Acta $612 \quad 2014 ; 130: 397-405$

613 [23] Ensafi AA, Jafari-Asl M, Rezaei B. Graphene nanosheets functionalized with 4614 aminothiophenol as a stable support for the oxidation of formic acid based on self615 supported $\mathrm{Pd}$-nanoclusters via galvanic replacement from $\mathrm{Cu}_{2} \mathrm{O}$ nanocubes. $\mathrm{J}$ $616 \quad$ Electroanal Chem 2014;731:20-7.

617 [24] Chen D, Wang X, Liu T, Wang X, Li J. Electrically conductive poly(vinyl alcohol) 618 hybrid films containing graphene and layered double hydroxide fabricated via layer619 by-layer self-assembly. ACS Appl Mater Inter 2010;2:2005-11.

620 [25] Gao Z, Wang J, Li Z, Yang W, Wang B, Hou M, et al. Graphene 621 nanosheet/ $\mathrm{Ni}^{2+} / \mathrm{Al}^{3+}$ layered double-hydroxide composite as a novel electrode for a 622 supercapacitor. Chem Mater 2011;23:3509-16.

623 [26] Li F, Bao Y, Chai J, Zh Q, Han D, Niu L. Synthesis and application of widely 624 soluble graphene sheets. Langmuir 2010;26:12314-9.

625 [27] Yang W, Gao Z, Wang J, Ma J, Zhang M, Liu L. Solvothermal one-step synthesis of $626 \mathrm{Ni}-\mathrm{Al}$ layered double hydroxide/carbon nanotube/reduced graphene oxide sheet 

Mater Inter 2013;5:5443-54.

629 [28] Rezaei B, Khosropour H, Ensafi AA, Dinari M, Nabiyan A. A new electrochemical 630 sensor for the simultaneous determination of guanine and adenine: using a Ni-Al631 layered double hydroxide/graphene oxide-multi wall carbon nanotube modified 632 glassy carbon electrode. RSC Advances 2015;5:75756-65.

633 [29] Berube V, Radtke G, Dresselhaus M, Chen G. Size effects on the hydrogen storage 634 properties of nanostructured metal hydrides: A review. Int $\mathrm{J}$ Energy Res $635 \quad 2007 ; 31: 637-63$.

636 [30] Attia NF, Geckeler KE. Polyaniline as a material for hydrogen storage applications. 637 Macromol Rapid Commun 2013;34:1043-55.

638 [31] Divya P, Ramaprabhu S. Hydrogen storage in platinum decorated hydrogen 639 exfoliated graphene sheets by spillover mechanism. Phys Chem Chem Phys $640 \quad 2014 ; 16: 26725-9$.

641 [32] Varin RA, Czujko T, Wronski ZS. Nanomaterials for solid state hydrogen storage, $642 \quad$ Springer, 2009.

643 [33] Ensafi AA, Jafari-Asl M, Rezaei B. Graphene/nano-porous silicon and graphene/ 644 bimetallic silicon nanostructures (Pt-M, M: Pd, Ru, Rh), efficient electrocatalysts for 645 the hydrogen evolution reaction. Phys Chem Chem Phys 2015;17:23770-82.

646 [34] Yan Y, Xia B, Qi X, Wang H, Xu R, Wang JY, et al. Nano-tungsten carbide 647 decorated graphene as co-catalysts for enhanced hydrogen evolution on molybdenum 648 disulfide. Chem Commun 2013;49:4884-6.

649 [35] Nguyen MP, Tran D, Pramana SS, Lee RL, Batabyal SK, Mathews N, et al. In 650 situ photo-assisted deposition of $\mathrm{MoS}_{2}$ electrocatalyst onto zinc cadmium 
651 sulphide nanoparticle surfaces to construct an efficient photocatalyst for hydrogen 652 generation. Nanoscale 2013;5:1479-82.

653

654

655

656

657

658

659

660

661

662

663

664

665

666

667

668

669

670 


\section{Legends for the figures:}

672 Fig. 1. A): FT-IR spectrum of Al-Ni/LDH-rGO with different percent of LDH on rGO 673 as: (a) $100 \%$, (b) 35\%, (c) 20\%, (d), 10\%, B): FT-IR spectrum of (a): Al-Zn/LDH-rGO, 674 (b): Al-Ni/LDH-rGO, and (c): Al-Cu/LDH-rGO.

675 Fig. 2. XRD pattern of (a): rGO, (b): Al-Zn/LDH-rGO, (c): Al-Cu/LDH-rGO, and (d): $676 \quad \mathrm{Al}-\mathrm{Ni} / \mathrm{LDH}-\mathrm{rGO}$.

677 Fig. 3. FE-SEM images of A-a): Al-Zn/LDH-rGO; B-a): Al-Cu/LDH-rGO; and C-a): Al678 Ni/LDH-rGO. TEM images of A-b) Al-Zn/LDH-rGO; B-b): Al-Cu/LDH-rGO; and C-b): $679 \quad \mathrm{Al}-\mathrm{Ni} / \mathrm{LDH}-\mathrm{rGO}$.

680 Fig. 4. A): Cyclic voltammograms of $\mathrm{Al}-\mathrm{Ni} / \mathrm{LDH}-\mathrm{rGO}$ after redox replacement in 681 different time in $0.5 \mathrm{~mol} \mathrm{~L}^{-1} \mathrm{H}_{2} \mathrm{SO}_{4}$ solution with a scan rate of $50 \mathrm{mV} \mathrm{s}^{-1}$. B): High 682 resolution XPS data for $\mathrm{Ni}$ in $\mathrm{Al}-\mathrm{Ni} / \mathrm{LDH}-\mathrm{rGO}$ and the curve fitting.

683 Fig. 5. A): Cyclic voltammograms of Pd\#Al-Cu/LDH-rGO-o-phenylenediamine with 684 different percent of LDH on rGO as: (a) 100\%, (b) $35 \%$, (c) $20 \%$, and (d) $10 \%$. B): 685 Cyclic voltammograms of (a) Pd\#Al-Zn/LDH-rGO- o-phenylenediamine, and (b) Pd\#Al686 Zn/LDH-EGO-o-phenylenediamine. C): Cyclic voltammograms of (a) Pd\#Al-Zn/LDH687 rGO-o-phenylenediamine, (b) Pd\#Al-Ni/LDH-rGO- $o$-phenylenediamine, and (c) Pd\#Al$688 \mathrm{Cu} / \mathrm{LDH}-\mathrm{rGO}-o$-phenylenediamine. Conditions: in $0.5 \mathrm{~mol} \mathrm{~L}^{-1} \mathrm{H}_{2} \mathrm{SO}_{4}$ solution with a 689 scan rate of $20 \mathrm{mV} \mathrm{s}^{-1}$.

690 Fig. 6. Cyclic voltammograms of Pd\#Al-Zn/LDH-rGO after electropolymerization with 691 A): $o$-Phenylenediamine, B): $p$-Phenylenediamine, C): $p$-Aminophenol, and D): $p$ 692 Aminothiophenol. Conditions: in $0.5 \mathrm{~mol} \mathrm{~L}^{-1} \mathrm{H}_{2} \mathrm{SO}_{4}$ solution with a scan rate of $20 \mathrm{mV} \mathrm{s}$ 6931. 
694 Fig. 7. Cyclic voltammograms of A): GCE after electropolymerization with $o$ 695 phenylenediamine, B) Al-Cu/LDH-rGO-o-phenylenediamine, and C): Pd\#Al-Cu/LDH696 rGO-o-phenylenediamine in $0.5 \mathrm{~mol} \mathrm{~L}^{-1} \mathrm{H}_{2} \mathrm{SO}_{4}$ solution with a scan rate of $20 \mathrm{mV} \mathrm{s}^{-1}$.

697 Fig. 8. Cyclic voltammograms of A): Pd\#Al-Cu/LDH-rGO, B): Pd\#Al-Ni/LDH-rGO, C): $698 \mathrm{Pd} \# \mathrm{Al}-\mathrm{Zn} / \mathrm{LDH}-\mathrm{rGO}$, and D): $\mathrm{Pd} / \mathrm{rGO}$, in $0.5 \mathrm{~mol} \mathrm{~L}^{-1} \mathrm{H}_{2} \mathrm{SO}_{4}$ solution with a scan rate of $69920 \mathrm{mV} \mathrm{s}^{-1}$.

700 Fig. 9 A): EIS (Nyquist plots) of (a) Pd/rGO, (b) Pd\#Al-Cu/LDH-rGO, (c) Pd\#Al701 Ni/LDH-rGO, and (d) Pd\#Al-Zn/LDH-rGO. B): EIS of (a) Pd\#Al-Zn/LDH-rGO, and (b) 702 Pd\#Al-Zn/LDH-rGO-o-phenylenediamine. Conditions: in $0.5 \mathrm{~mol} \mathrm{~L}^{-1} \mathrm{H}_{2} \mathrm{SO}_{4}$ solution at 703 a potential of $-300 \mathrm{mV}$ vs. $\mathrm{Ag} / \mathrm{AgCl}$.

704 Fig. 10. $1^{\text {th }}$ (a) and $200^{\text {th }}$ (b) successive cyclic voltammograms of A): Pd\#Al-Cu/LDH, 705 B): Pd\#Al-Ni/LDH-rGO, C): Pd\#Al-Zn/LDH-rGO, D): Pd\#Al-Zn/LDH-rGO-o706 phenylenediamine, and E): Pd\#Al-Cu/LDH-rGO-p-phenylenediamine. Conditions: in 0.5 $707 \mathrm{~mol} \mathrm{~L}^{-1} \mathrm{H}_{2} \mathrm{SO}_{4}$ solution with a scan rate of $20 \mathrm{mV} \mathrm{s}^{-1}$.

708 Fig. 11. Five hundred successive cyclic voltammograms of A): Pd\#Al-Zn/LDH-rGO-o709 phenylenediamine, B): Pd\#Al-Cu/LDH-rGO-o-phenylenediamine, and C): Pd\#Al$710 \mathrm{Ni} / \mathrm{LDH}-\mathrm{rGO}-o$-phenylenediamine. D): 200 successive cyclic voltammograms of $711 \mathrm{Pd} / \mathrm{rGO}-o$-phenylenediamine. Conditions: in $0.5 \mathrm{~mol} \mathrm{~L}^{-1} \mathrm{H}_{2} \mathrm{SO}_{4}$ solution with a scan rate 712 of $20 \mathrm{mV} \mathrm{s}^{-1}$. 


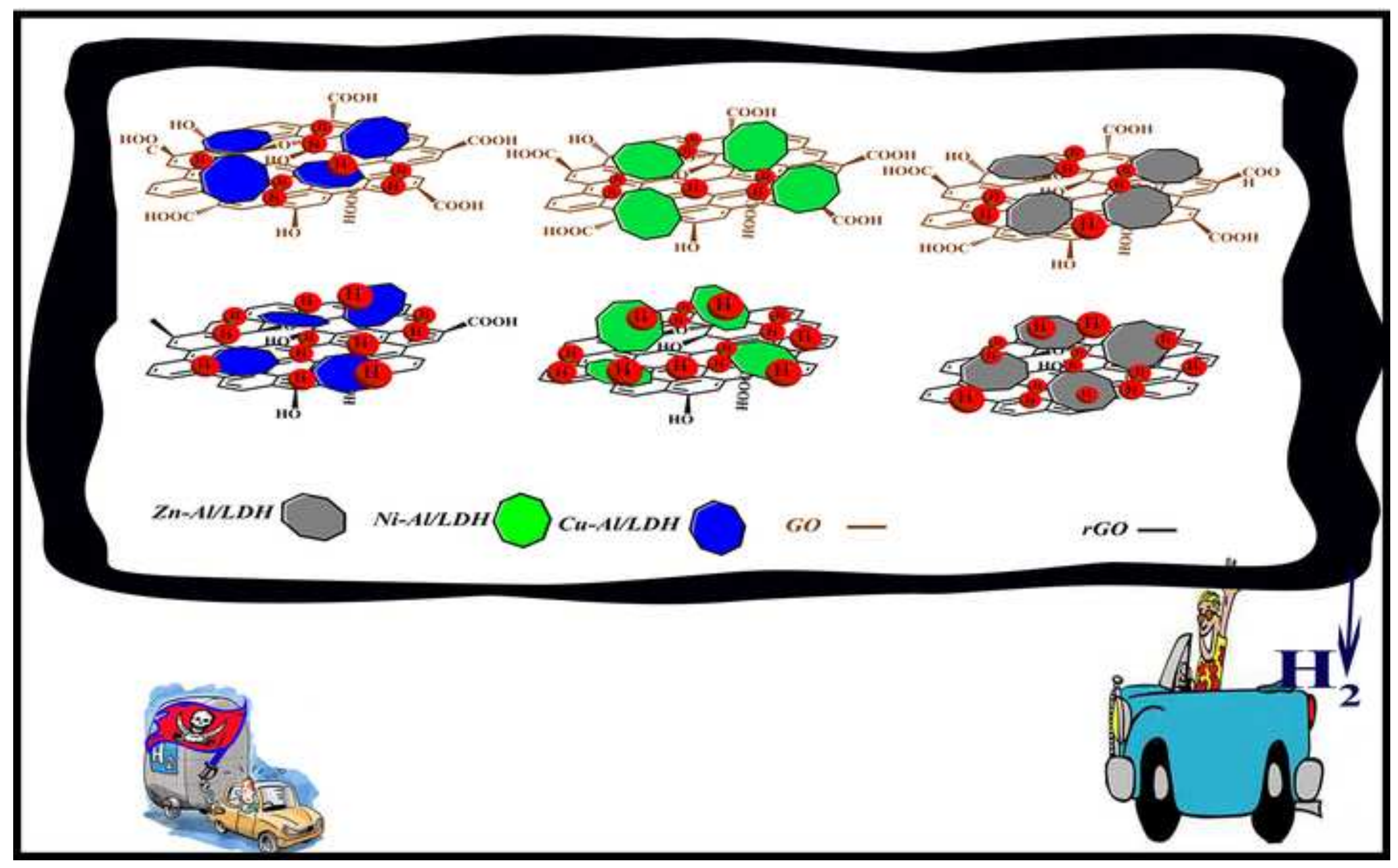

$C u-A L L D H$

$r G O$ 


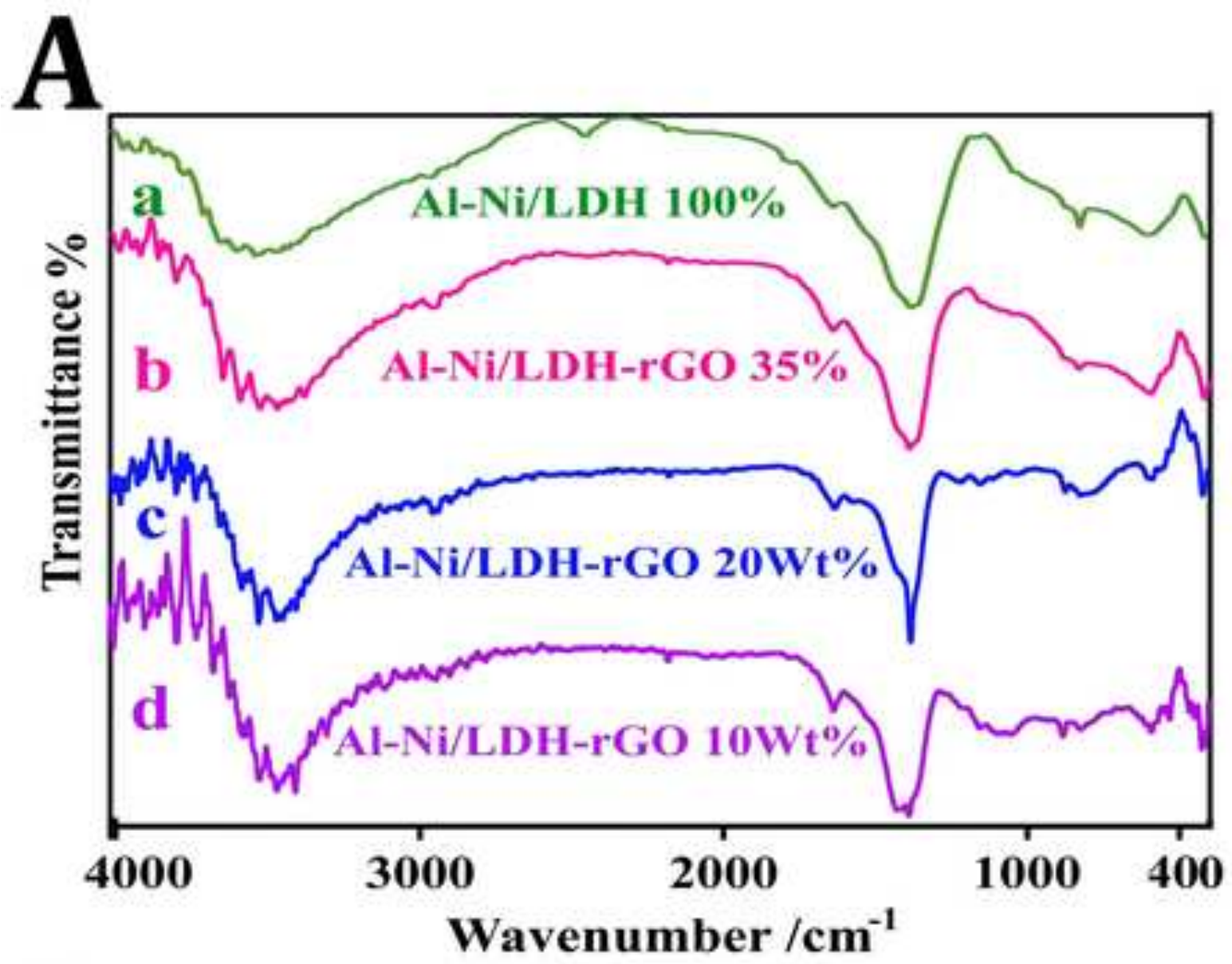

\section{B}

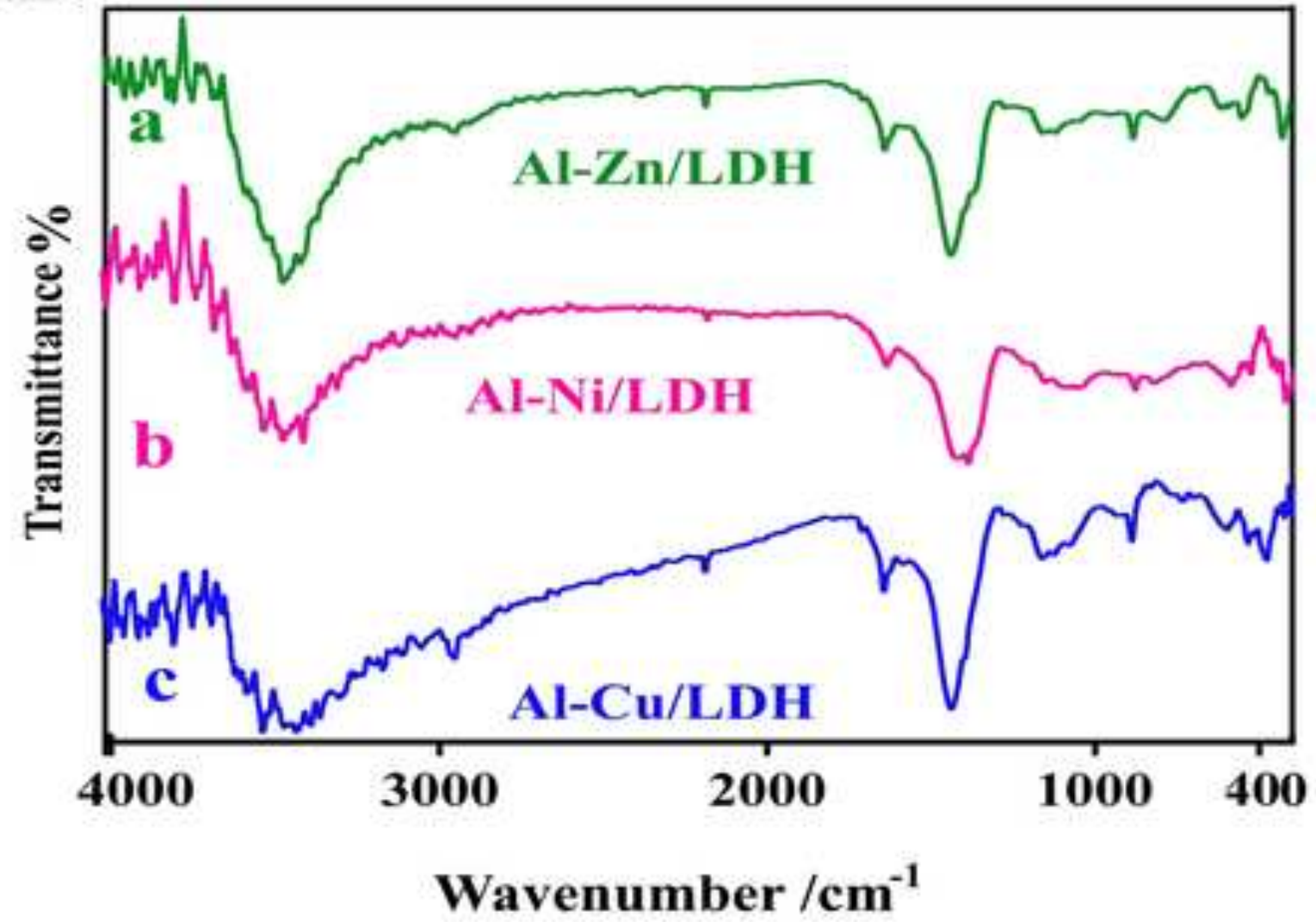




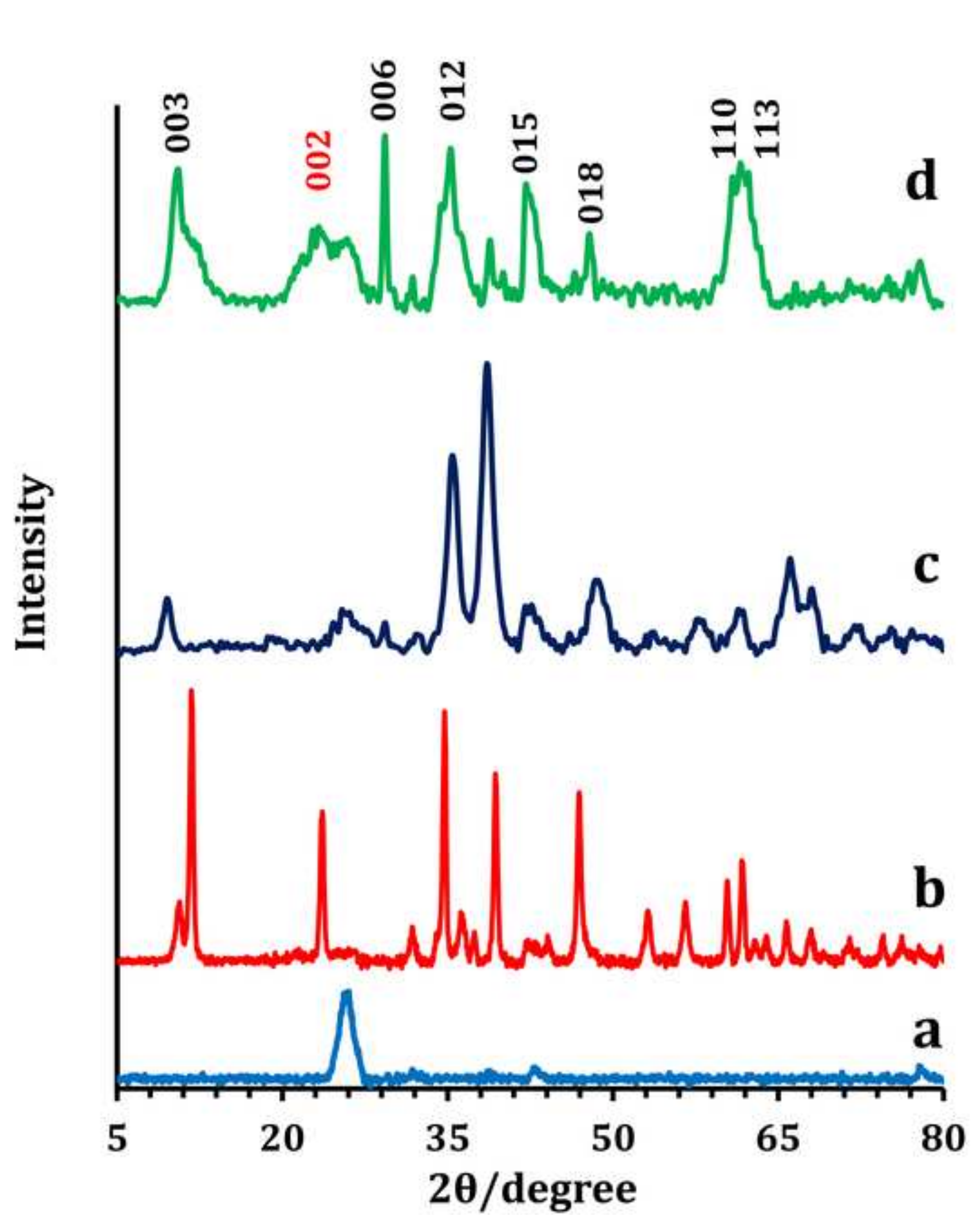

Figure 2

.

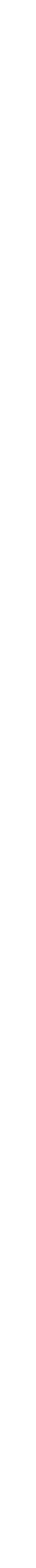



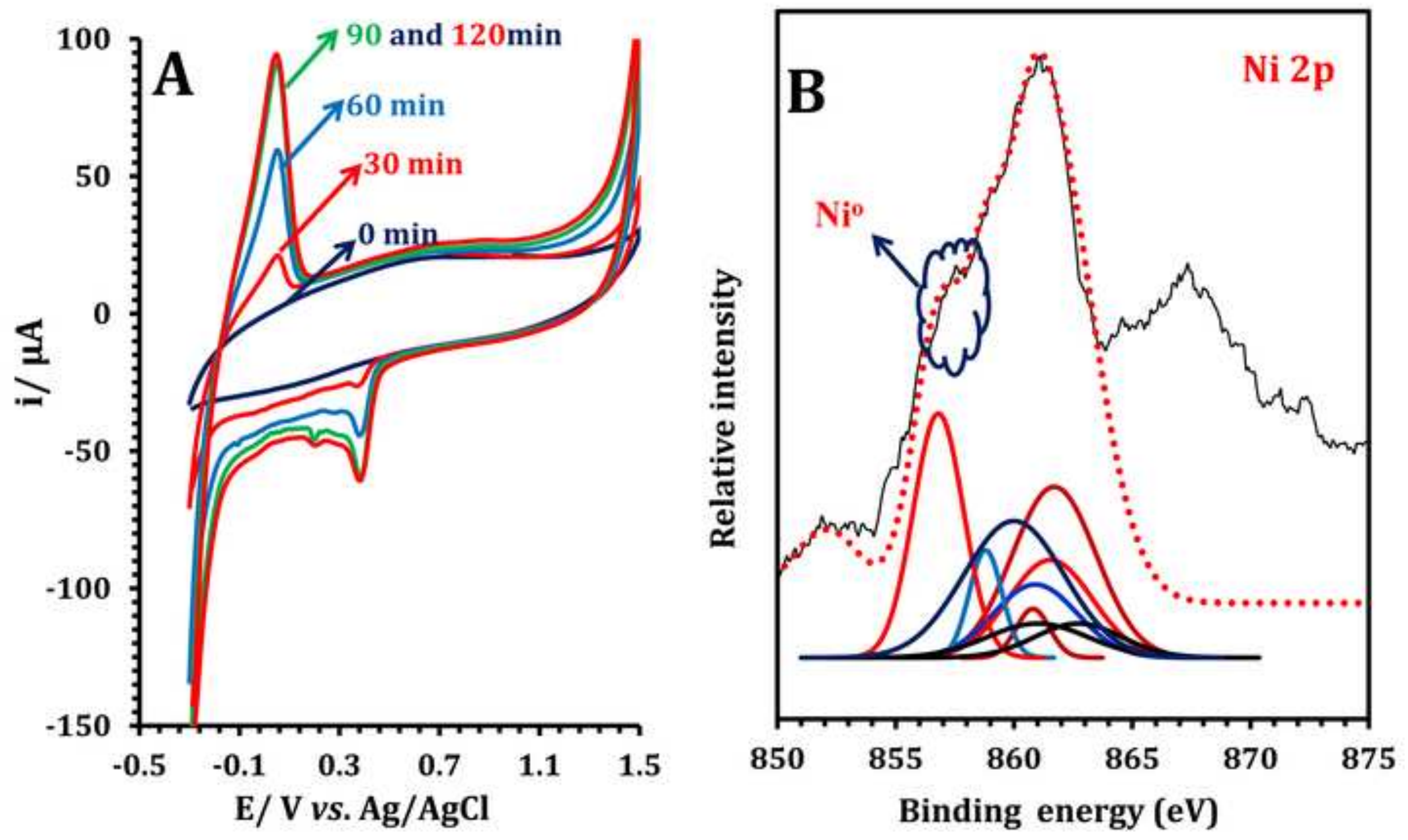

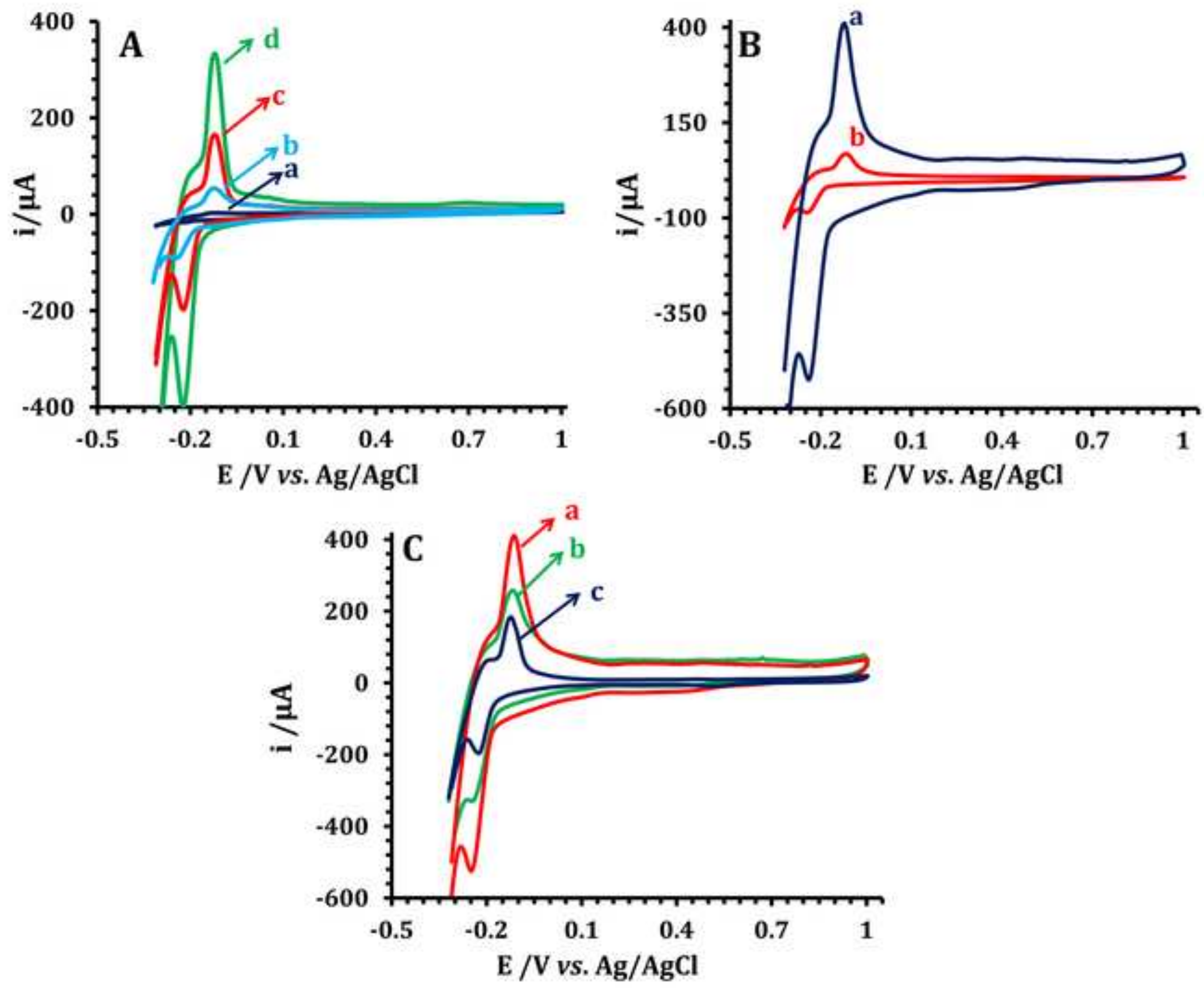
Figure 6

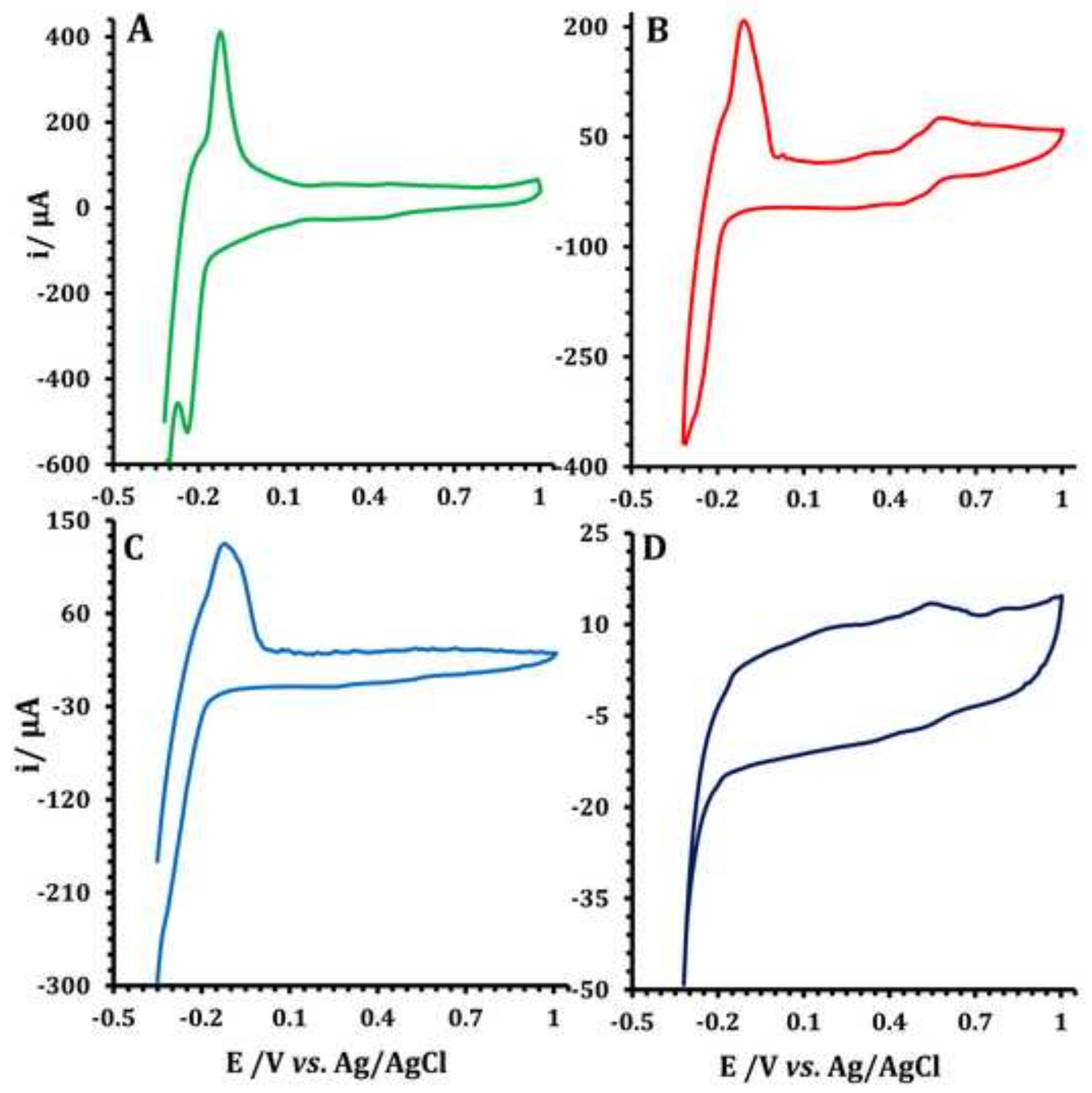



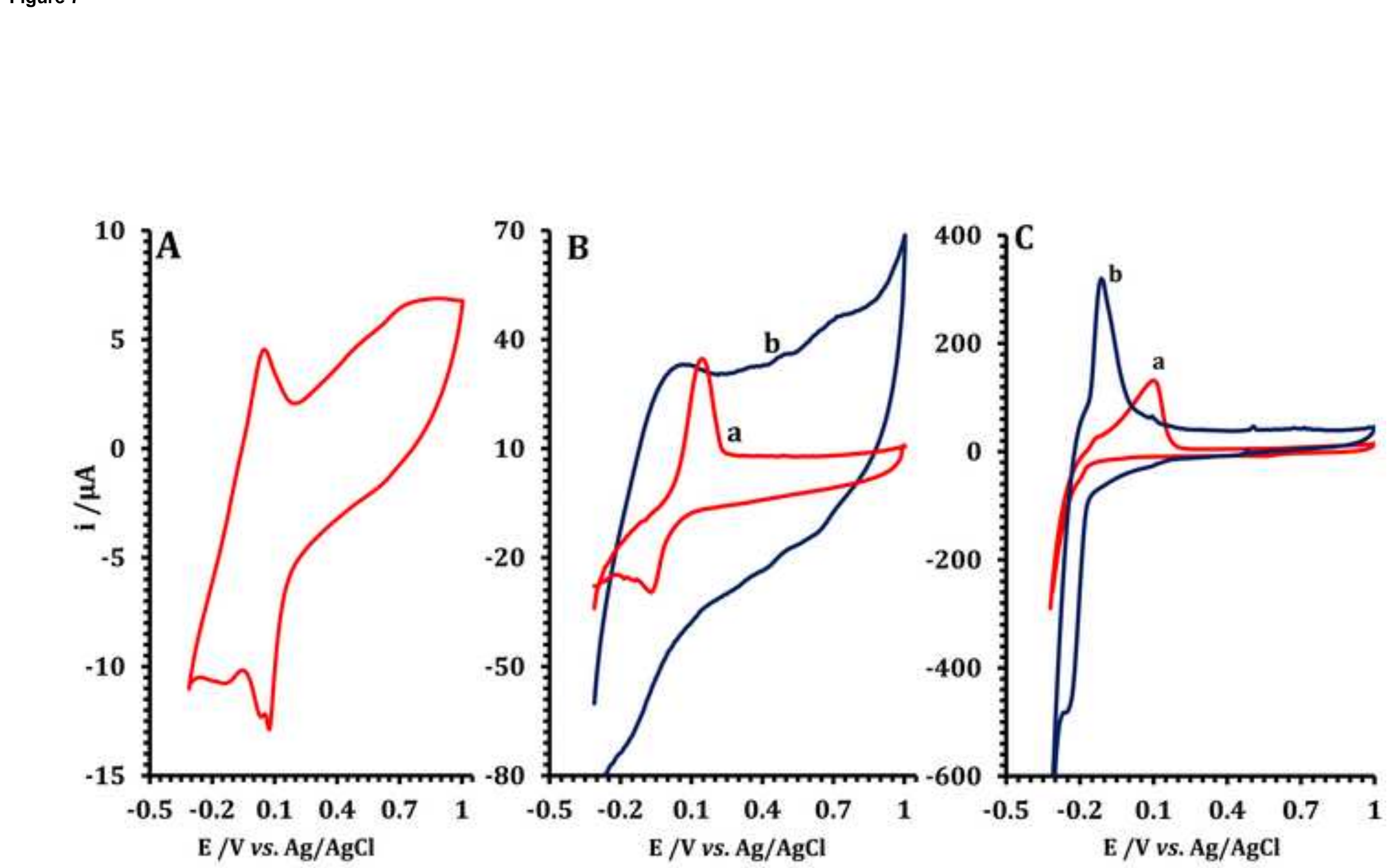

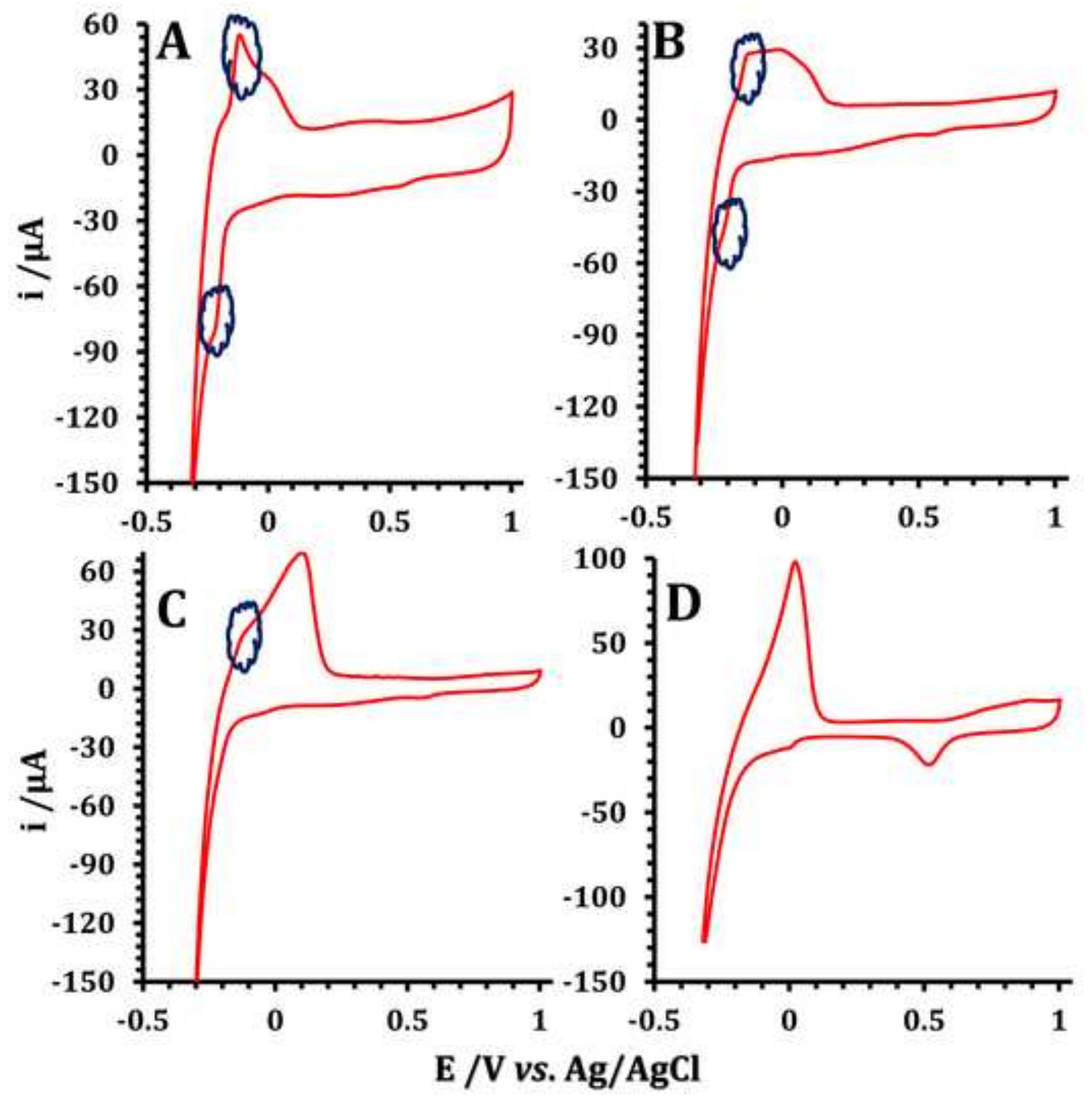

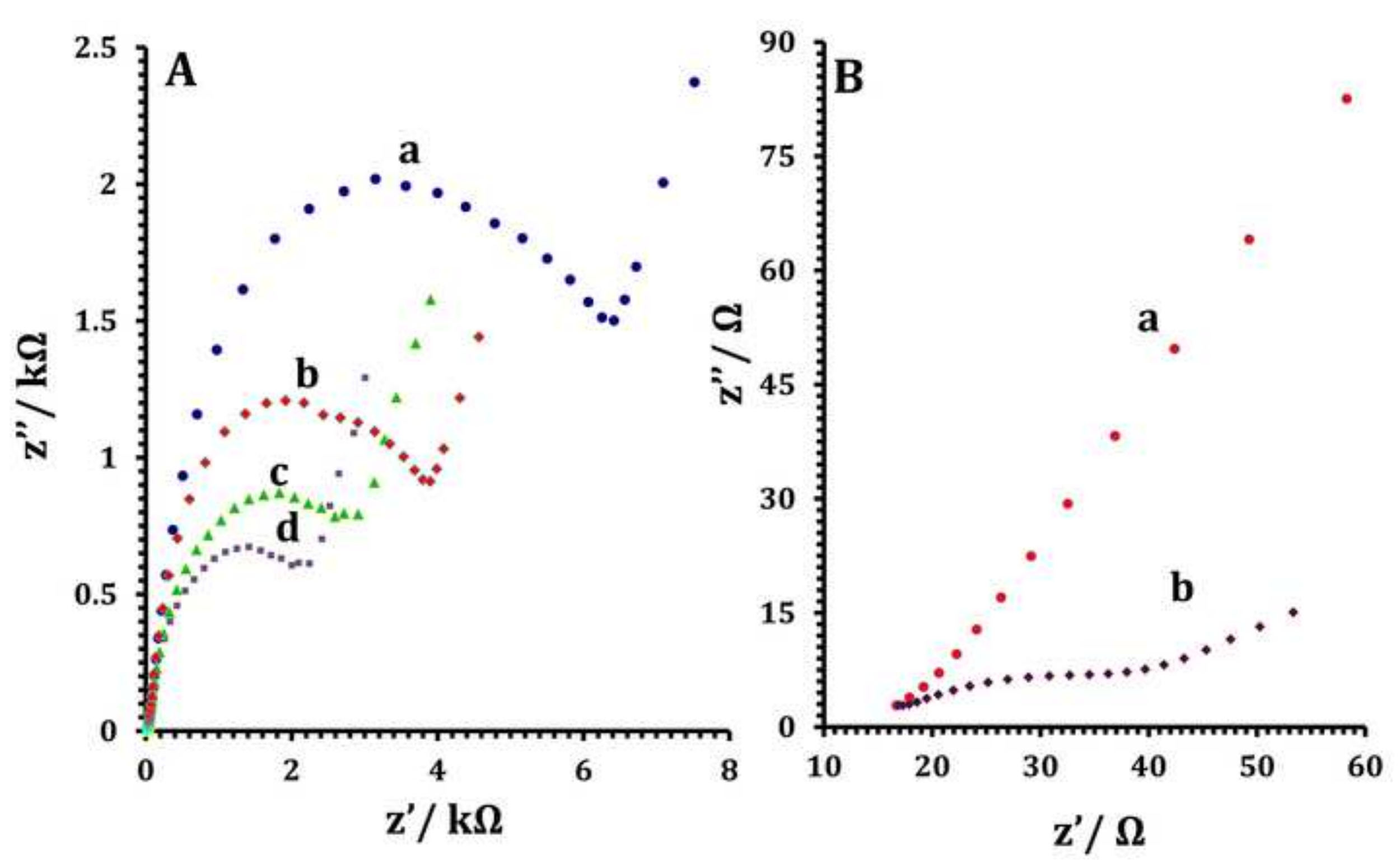

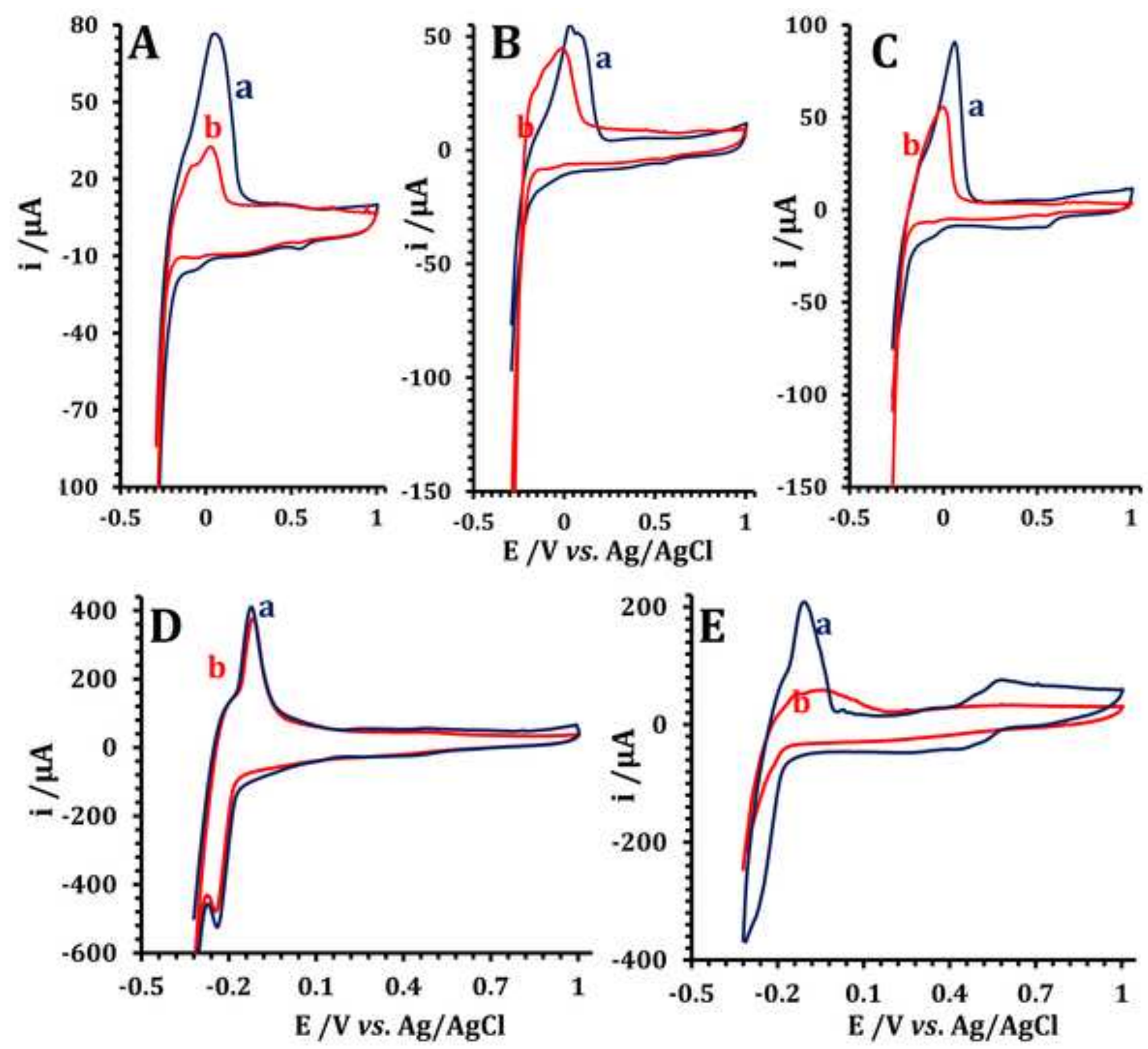


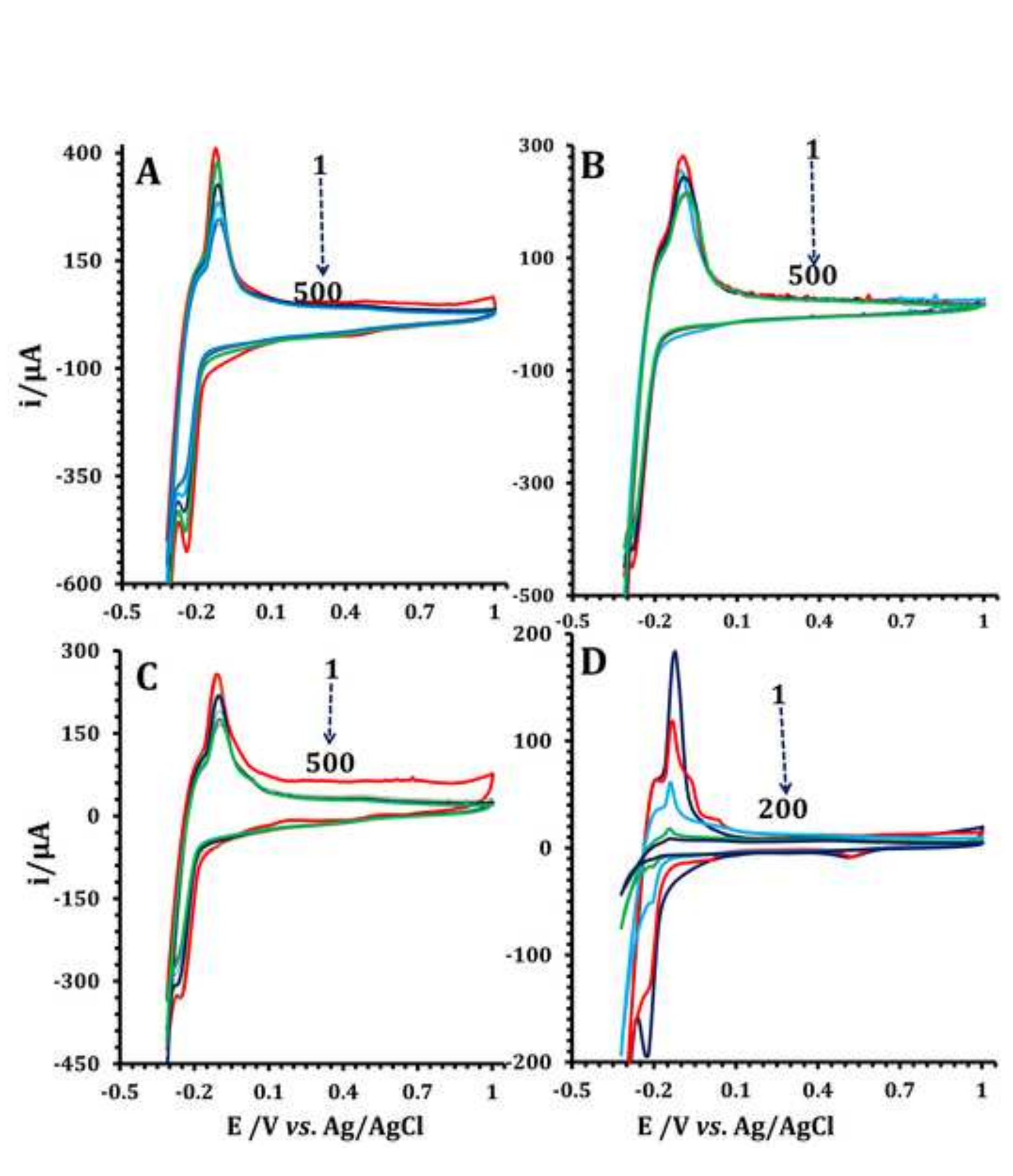

Figure 11

Figure 11

.

政

.



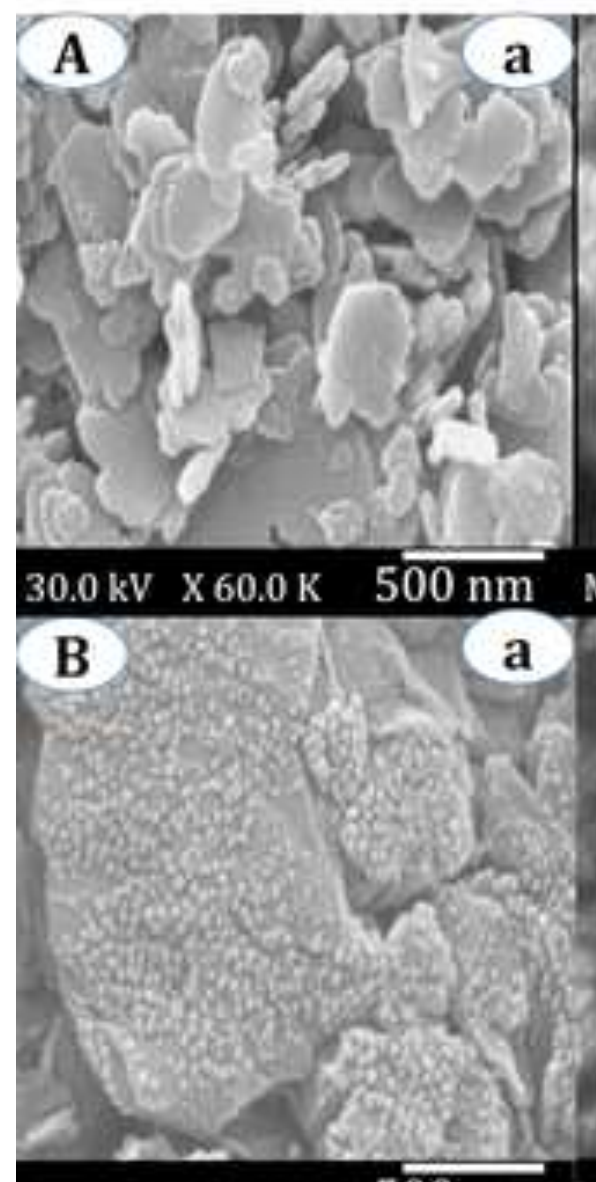

Mode: BF HT: $150 \mathrm{kV}$
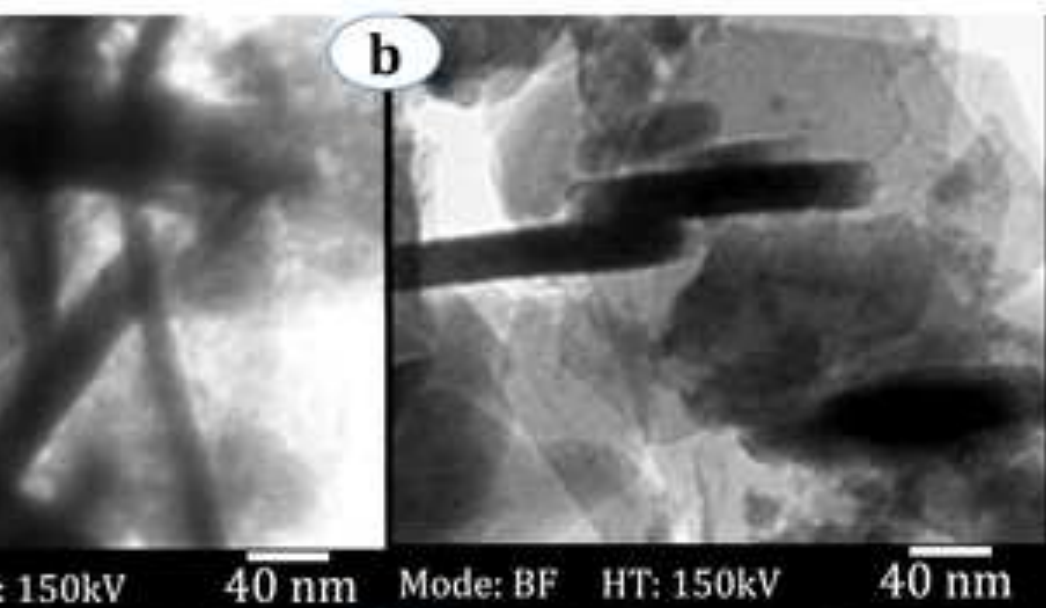

$30.0 \mathrm{kV} \times 60.0 \mathrm{~K} \quad 5 \overline{000 \mathrm{~nm}}$ Mode: BF HT: $150 \mathrm{kV}$

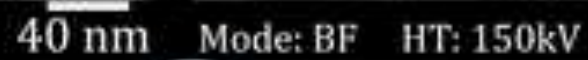

$40 \mathrm{~nm}$

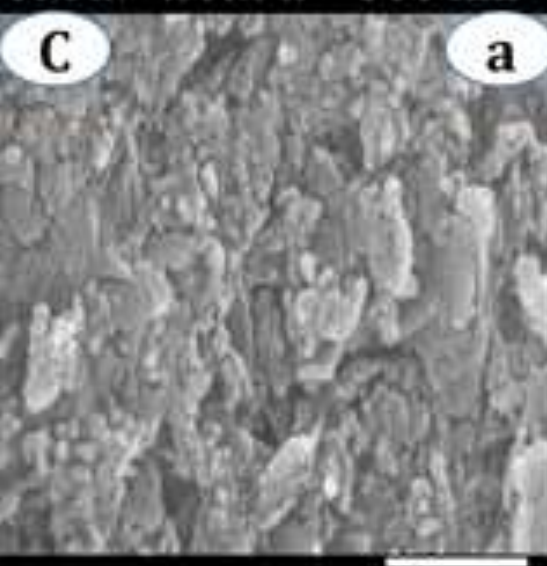

$30.0 \mathrm{kV} \times 60.0 \mathrm{~K}$ 